\title{
Una estética del hacer. Miradas sobre las bolsas prehispánicas tardías de Doncellas (Puna septentrional argentina)
}

Fecha de recepción: 13/01/2019

Fecha de aceptación: 30/03/2019

\section{Resumen}

Basado en el estudio de una selección de bolsas tejidas recuperadas de enterratorios prehispánicos tardíos durante la expedición de Eduardo Casanova a Doncellas (Puna septentrional argentina) en 1941-1943, este artículo explora las opciones estéticas hechas por las tejedoras al hilar y tejer las bolsas. La autora utiliza su propio trabajo de campo etnográfico como participante y observadora en Isluga, norte de Chile, entre pastores de llamas y alpacas, para indagar en las prácticas del pasado cuando las tejedoras utilizaban el vellón obtenido del entorno en un mundo lleno de significados. Se analiza la conformación de listas angostas y peinecillos, un diseño formado por pequeñas barras horizontales en tejido llano, así como el uso de hilos de urdimbre transpuesta y trama múltiple en un tejido con faz de urdimbre. Este análisis proporciona una pista para considerar cómo los actos de tejer pueden estar relacionados con las predilecciones estéticas de las tejedoras. Debido a que la expresión estética surgió de sus prácticas diarias, se sugiere que las tejedoras podrían haber considerado el sentimiento estético como una condición inmanente, en lugar de ser importado de un plano de experiencia elevado no diario.

\section{An aesthetics of making. Reflections on the late pre-Hispanic bags of Doncellas (Northern Puna, Argentina)}

Based on a study of woven bags collected from late pre-Hispanic burials during Eduardo Casanova's expedition to Doncellas (northern Puna of Argentina) in 1941-1943, this article explores aesthetic choices made by weavers in spinning and weaving the bags. The author relies on her own ethnographic fieldwork as a participant observer in

Palabras clave

Estética cotidiana Inmanencia Destreza manual Tejer División sexual del trabajo
Keywords

Everyday aesthetics Immanence Manual skill Weaving Sexual division of labour 


\section{Mots clés}

Esthétique quotidienne Immanence Habileté manuelle Tissage Division sexuelle du travail
Isluga, northern Chile, among llama and alpaca herders, to inquire into past practices when the weavers used the fleece obtained from their environment in a world full of meanings. The conformation of narrow stripes and peinecillos, a design which creates little horizontal bars in a plain weave textile, is analysed, as well as the use of transposed warp and multiple weft in warp-faced textiles. This analysis provides a platform for considering how acts of weaving may be related to the weavers' aesthetic predilections. Because aesthetic expression emerged from daily practices, it is suggested that the weavers considered aesthetic feeling to be an immanent condition, rather than being imported from a heightened plane of experience.

\section{Une esthétique de faire. Regards sur les sacs préhispaniques tardifs de Doncellas (Puna nord, Argentine)}

\section{Résumé}

Dans cette étude de sacs tissés retrouvés dans des sépultures préhispaniques tardives au cours de l'expédition d'Eduardo Casanova à Doncellas (Puna nord, Argentine) en 1941-1943, sont présentés les choix esthétiques faits par les tisserandes pour filer et tisser ces objets. L'auteure s'appuie sur sa propre expérience ethnographique de l'observation participante à Isluga, dans le nord du Chili, parmi des éleveurs de lamas et d'alpagas, pour enquêter sur les pratiques du passé lorsque les tisserandes utilisaient la toison obtenue de leur environnement dans un monde plein de significations. La composition de bandes étroites et de peinecillos, un dessin qui crée des petites barres horizontales dans une toile à dominante chaîne, est analysée, ainsi que l'utilisation de fils de chaîne transposés et de trames multiples dans des textiles à dominante chaîne. Cette analyse offre le cadre adéquat pour examiner comment la pratique du tissage peut être liée aux choix esthétiques des tisserandes. Parce que l'expression esthétique a émergé de leurs pratiques quotidiennes, il est suggéré que les tisserandes auraient pu considérer le sentiment esthétique comme une condition immanente, au lieu dềtre importée d'un niveau d'expérience surélevé.

En este artículo, deseo explorar algunos aspectos de la estética del hacer - principalmente en las acciones de hilar, tejer y coser- en un estudio de bolsas provenientes de los contextos funerarios de Doncellas, departamento de Cochinoca, en la Puna jujeña. Mi perspectiva es la de una etnógrafa que ha realizado trabajos de campo como participante y observadora en la vida de las pastoras-tejedoras actuales en el altiplano chileno. Las bolsas que ilustran este artículo se tejieron a partir de hilos hechos de fibras de camélidos. En su producción estuvo involucrada toda una secuencia de transformaciones, comenzando con el pastoreo de los camélidos en las vegas y el crecimiento del vellón a medida que los camélidos consumían los pastos. Con el trabajo de manos humanas, el vellón se esquiló de llamas vivas o se sacó de las pieles de llamas sacrificadas; se lo tiñó y se lo hiló en hilo antes de tejerlo en tela. Al final de una vida humana, las bolsas se colocaron dentro de una tumba y se devolvieron a la tierra junto con el cuerpo del difunto. Pero en lugar de descomponerse y reincorporarse a la tierra, estos restos humanos y textiles fueron desenterrados durante una expedición hecha por Eduardo Casanova a Doncellas en 1941-1943. Se sacaron los restos humanos y ajuares con el propósito de conservarlos. Ahora se encuentran en el Museo Etnográfico "Juan B. Ambrosetti" de Buenos Aires y en el Museo Arqueológico y Antropológico "Dr. Eduardo Casanova" de Tilcara, ambos pertenecientes a la Facultad de Filosofía y Letras de la Universidad de Buenos Aires. 
Los textiles se encontraron en una alineación de aproximadamente doscientas tumbas a lo largo de un farallón cerca del pueblo de Doncellas (Pérez de Micou, 2009: 77). La datación C-14 sobre hilos y algunos estudios de los ajuares indican que casi todos los enterratorios corresponden a un lapso de tiempo desde al menos $1250 \mathrm{~d}$. C. hasta el momento del contacto español (Pérez de Micou, 2009: 82). ${ }^{1}$ Agüero (2018) sugiere que las bolsas pertenecen a un período de tiempo algo más estrecho entre 1350 y 1500, coincidiendo con un aumento de caravanas de llamas en la región y la expansión incaica. Este artículo se centra en las bolsas tejidas con urdimbre y trama de Doncellas porque sus características técnicas y visuales sugieren que poseen una identidad colectiva. La manera en que las bolsas pueden expresar las elecciones estéticas de las tejedoras permite considerar la existencia de una noción de "identidad".

Aunque algunas de las bolsas se deterioraron en la tumba donde sufrieron daños por la acción de insectos o entraron en contacto con los fluidos corporales en descomposición, también es evidente que muchas ya estaban en mal estado cuando los dolientes las colocaron junto a la persona fallecida. Veintiocho bolsas de las setenta y nueve estudiadas por Rolandi de Perrot (1979: 32) fueron reparadas por zurcido y en muchos casos se acondicionaron también los hilos de la costuras (Figura 1)². Estas bolsas proporcionan un contraste con la cerámica, especialmente la cerámica no local, de filiación Yavi o Inka, que no muestra rastros de uso doméstico (Pérez y Killian Galván 2011:95)³.

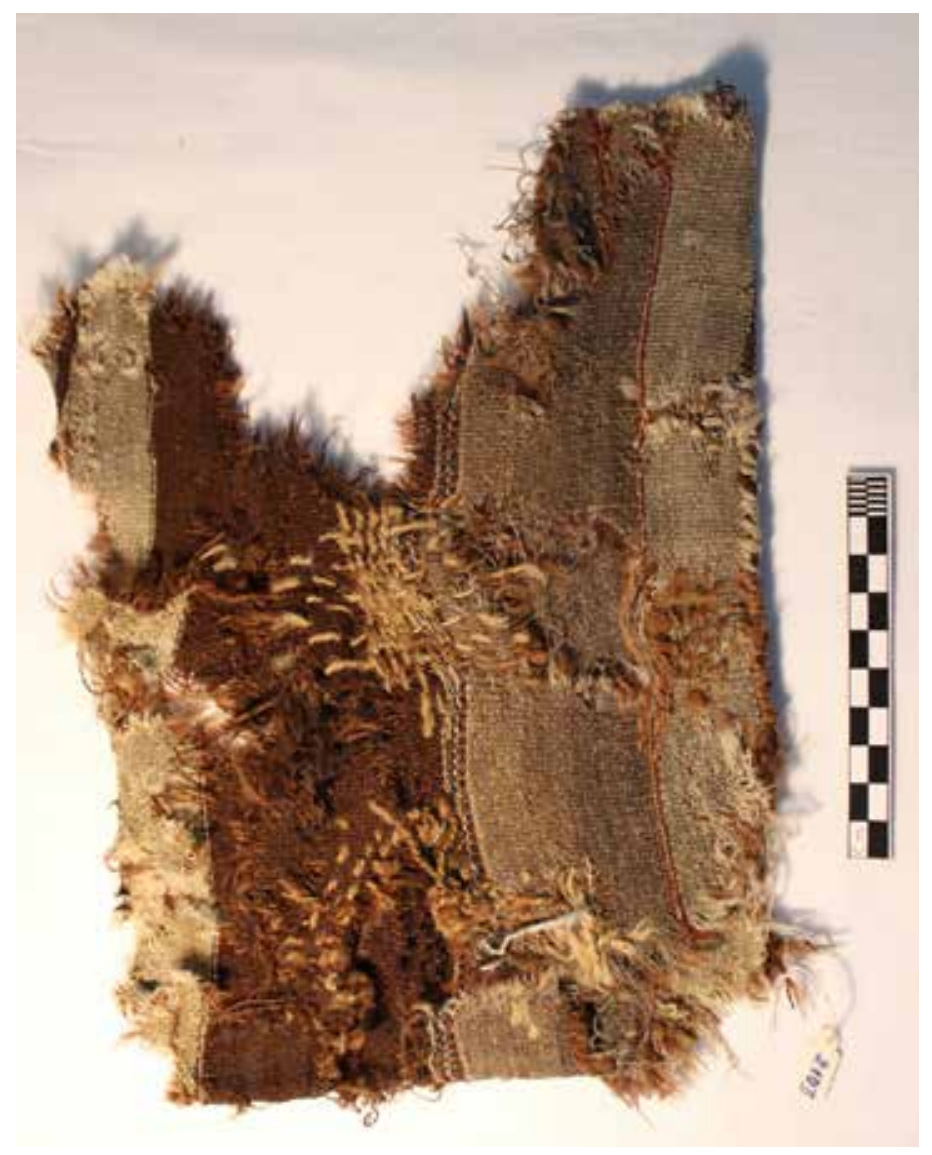

Figura 1a. Bolsa con una disposición de color asimétrica de los enterratorios de Doncellas. № 2103, 42.558 (Museo Arqueológico "Dr. Eduardo Casanova", Centro Universitario Tilcara, Facultad de Filosofía y Letras, Universidad de Buenos Aires). 
Figura 1b. Detalle de la bolsa en Figura 1a donde se nota el tejido original de la tela y algunas áreas de zurcido en hilos gruesos de color marrón claro.

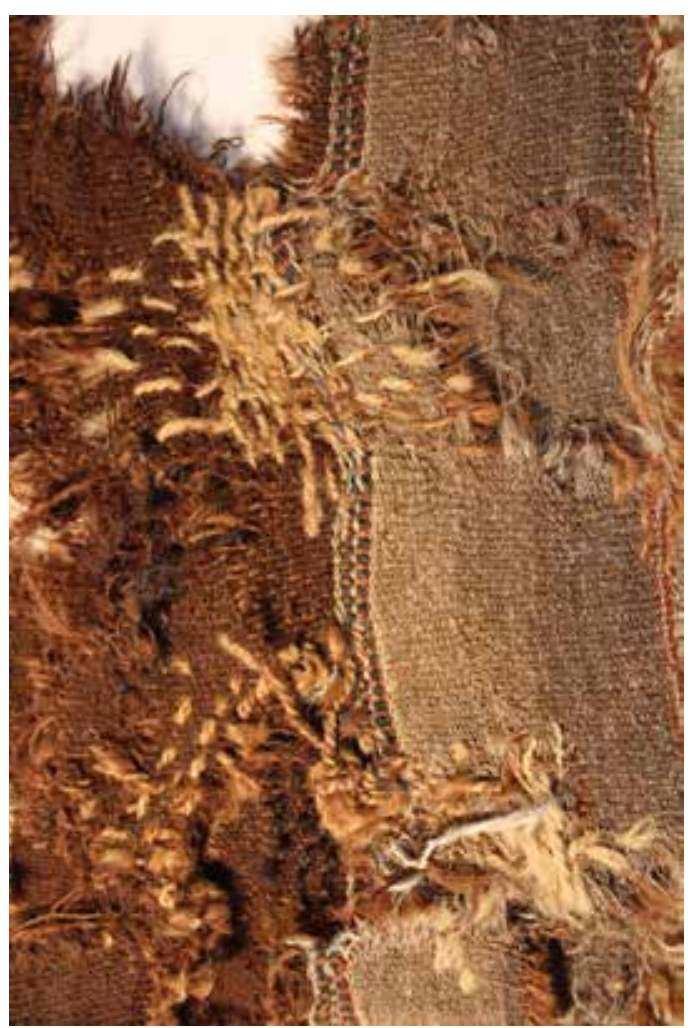

Figura 1c. Detalle de la costura en la bolsa en la Figura $1 a$, indicando el punto corrido envuelto original en un hilo de color marrón oscuro acondicionado por un hilo grueso de color marrón claro.

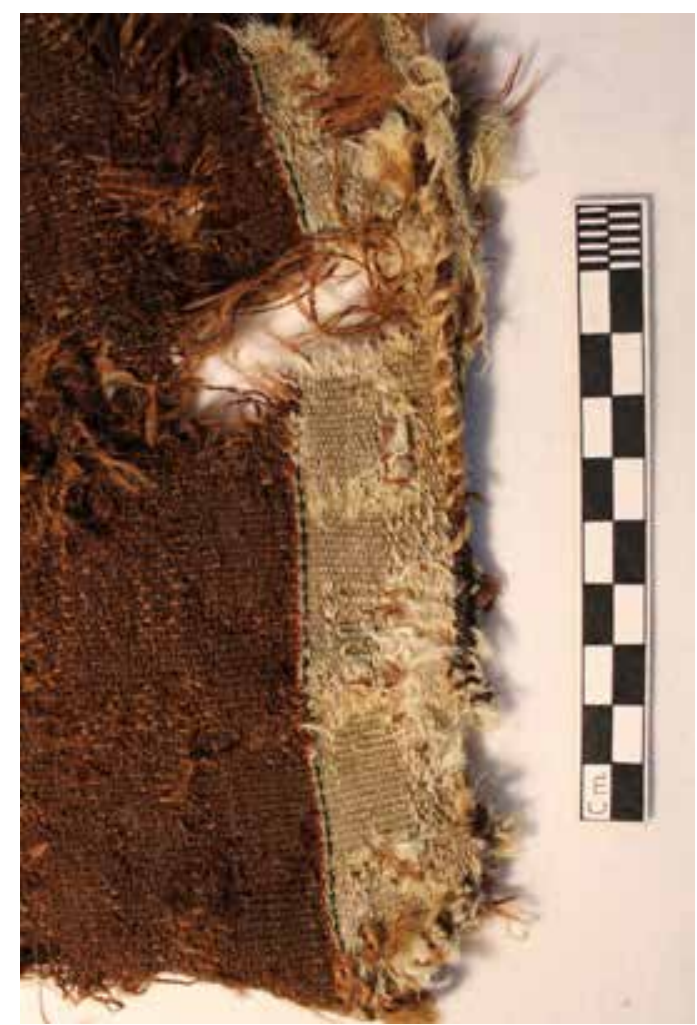


A unos 3.500-3.900 m.s.n.m., el ambiente frío y semidesértico de Doncellas es típico de la Puna, donde la gente vivía en asentamientos con un economía basada en la crianza de camélidos, el cultivo de algunos productos agrícolas y la explotación de sal (Alfaro de Lanzone, 1988: 13). Ottonello de García Reinoso y Ruthsatz (1982: 115) sugieren que aunque existía un patrón de asentamiento de conglomerados, los miembros de la comunidad conservaron el acceso a un tipo de vida rural "con todos realizando tareas similares". El hilado y el tejido habrían ocupado una gran parte del tiempo de la gente porque la cantidad de hilo necesaria para tejer prendas para vestir a todos los miembros de la familia nunca debe ser subestimada. En la excavación del Recinto 2 del Yacimiento de río Doncellas, Alfaro de Lanzone (1988: 38) observaba cinco palos desgastados hacia el centro de la pieza, "en posición horizontal y uno a lado del otro", y sugirió que eran las partes de un telar.

Los miembros de la comunidad también fabricaban su propia cerámica. Alfaro de Lanzone $(1988: 38,94)$ interpretó algunos cuencos con un “asa” en la concavidad interior como tazones utilizados para hilar. Se piensa que otra categoría de cerámica, el vaso chato, servía para el mismo fin. En una investigación de cómo se realizaron estos vasos, Pérez (2013: 392) no descubrió evidencias definitivas para demostrar si estos cumplían tal función, pero observó ejemplares con un orificio redondo en la base, encontrados en la zona de Doncellas, que serían adecuados para tal propósito. Dicha autora también mencionó que había husos y torteros de madera presentes entre los ajuares de las tumbas (Pérez, 2013: 387).

Si de hecho los vasos chatos se usaron para hilar, los hilanderos y las hilanderas habrían pasado tiempo hilando en posición sentada, tal vez con el vaso chato descansando en el regazo o colocado en el suelo para apoyar la punta de un huso de mano. Un momento adecuado para tal trabajo habría sido la noche, quizás cerca del fuego cuando la familia se juntaba para preparar la comida. Al caer la noche, cuando la temperatura bajaba, el vellón de llama habría sido más fácil de hilar junto al calor del fuego. Este escenario no descarta la posibilidad de que la gente también hilara en un huso sin la ayuda de un vaso chato durante las horas del día, especialmente cuando las llamas pastoreaban en las vegas. En una comunidad con acceso al vellón de camélido, todos - mujeres, hombres y niños - probablemente habrían sido productores de diferentes tipos de hilo para satisfacer la necesidad de elaborar ropa, bolsas y sogas para la vestimenta, el almacenamiento y las tareas de pastorear las llamas, tanto como para el transporte con llamos cargueros.

En un sentido, entonces, hilar y tejer eran quehaceres rutinarios. Sin embargo, habría momentos durante el ciclo del año en los que se produciría una mayor necesidad de hilar y tejer que en otras ocasiones. En las comunidades andinas de hoy, el hilado y el baile son actividades mutuamente excluyentes; nunca se ve a alguien, por ejemplo, hilando en una fiesta donde se toma chicha (Meisch, 1986a: 28). Por otro lado, los meses previos al Carnaval son períodos de actividad intensa de tejido. Este período coincide con la temporada de lluvias en los Andes centro sur, lo que significa que las llamas comen más tranquilamente en los pastizales. Las tejedoras de Isluga pueden pasar más tiempo tejiendo que en la estación fría y ventosa, cuando tienen que prestar más atención a sus rebaños de llamas (Dransart, 2002: 58). Condiciones algo similares tienen relevancia para el río Doncellas, cuyo caudal se incrementa cada año con las lluvias de verano (Alfaro de Lanzone, 1988: 13).

Zorn (1992: 152) observó que en lo que ella llamó la "vida cotidiana" (a diferencia de los días de fiesta) las tejedoras de la isla de Taquile eran "obsesivas" con la atención que dedicaban a tejer. Situó el concepto de la "vida cotidiana" frente a las diferentes experiencias generacionales de las tejedoras y a cómo intentaron equilibrar las demandas tradicionales con las posibilidades modernas. La cantidad de textiles colocados en los 
enterratorios de Doncellas (además de las prendas que la gente utilizó durante su vida, que no han subsistido) indica que tejer era una actividad cotidiana que exigía el tipo de atención descrita por Zorn. Y, dado el conocimiento contextual que está disponible para la forma de vida en Doncellas durante los tiempos prehispánicos tardíos, es posible también explorar las actividades de tejer que han dejado huellas en las bolsas para exponer algunas de las estrategias estéticas involucradas en la producción de los textiles.

Mandoki (2008) ve la estética como algo bello además de poseer otras propiedades, entre las cuales podríamos incluir, por ejemplo, el acto racional de contar los hilos que está implícito en el arte de tejer. "Al hacer arte", explica, "como al hacer ciencia, es imprescindible una actividad lúdica y apreciativa, la absorción en el proceso de comprensión con el enorme placer que implica, una admiración por el orden de las formas y de las estructuras, un goce..." (Mandoki, 2008: 41). Esta propensión a tanta absorción en una tarea que uno tiene que terminar tal vez es otra forma de explicar lo que Zorn quiso decir al describir la actitud de las tejedoras de Taquile como "obsesiva".

Parece que el ritmo de trabajo en Doncellas se basó en gran medida en la combinación de actividades de pastoreo, tejido, cultivo de plantas, búsqueda de sal de los salares y de arcilla para alfarería. Las particularidades de esta manera de vivir también se presentaron en mayor o menor medida en otras comunidades de la Puna. Tastil, en la provincia de Salta, tenía una concentración mucho mayor de viviendas que Doncellas. Tomando prestado un criterio dado por J. E. Hardoy en 1964 para categorizar los asentamientos densamente conglomerados, Cigliano y Raffino (1973: 167) caracterizaron a Tastil como "un lugar donde la gente residía y trabajaba". Cualesquiera que sean las diferencias entre las dos comunidades, la combinación de vivir y trabajar tanto en Tastil como en Doncellas estaba fuertemente orientada hacia las actividades de hilar y tejer. Eran comunidades en las que el hilado y el tejido constituían la idea del trabajo productivo. ${ }^{5}$

\section{Un excedente de significados: desplegando algunas tradiciones textiles}

El diseño de casi todas las bolsas de Doncellas está organizado en una serie de listas, la mayoría de las cuales tiene colores sin teñir de vellón de camélido. Van acompañadas por listas estrechas de peinecillo y otras listas angostas en colores contrastantes, que pueden estar teñidas de rojo, azul, amarillo o verde. Las características formales de estos tejidos a listas son el resultado de prácticas heredadas del pasado. A lo largo de los Andes, han existido tradiciones duraderas para efectuar diseños textiles mediante el uso de listas en la urdimbre. El análisis detallado de los textiles de la Huaca Prieta en el norte del Perú demuestra que a través del tiempo hubo una disminución en el uso de imágenes figurativas logradas mediante la técnica de torzal en textiles encordelados y un aumento en el uso de listados por urdimbre en tejido llano. ${ }^{6}$ Este cambio fue acompañado por un incremento en la cantidad de textiles producidos (Bird et al., 1985). Empero incluso en los textiles encordelados tempranos hechos de algodón, que datan de alrededor de $6200 \mathrm{AP}$, las listas ya se producían a través de secuencias de hilos de urdimbre de color blanco sin teñir e hilos teñidos de azul con índigo (Splitstoser et al., 2016).

En un estudio sobre el desarrollo del tejido por telar en Perú, Doyon-Bernard (1990) llama la atención sobre la importancia del cruce en la urdimbre para crear diseños e indica que el uso del lizo se remonta a 4000 o 3800 años AP. Hoy en día un palo separador y un lizo ordenan los hilos en dos series por medio del cruce, al que las tejedoras de habla aymara denominan qata. Se lo establece en el proceso de urdir el telar antes de armar el lizo (Figura 2a). Durante este proceso, una tejedora cuenta los hilos en pares, en la forma de una ida y una vuelta de la urdimbre. Para tejer un diseño más elaborado, 
como en la lista central de la Figura 2b, hay otro ritmo para contar, se dobla la ida y vuelta con dos colores y cada par consta de cuatro hilos (Desrosiers, 2013: 482). Como se explicará más adelante, a veces la tejedora también inserta hilos en determinados momentos que son únicos o impares. Estos hilos carecen de compañero, pero sirven para articular el diseño en un tejido llano.
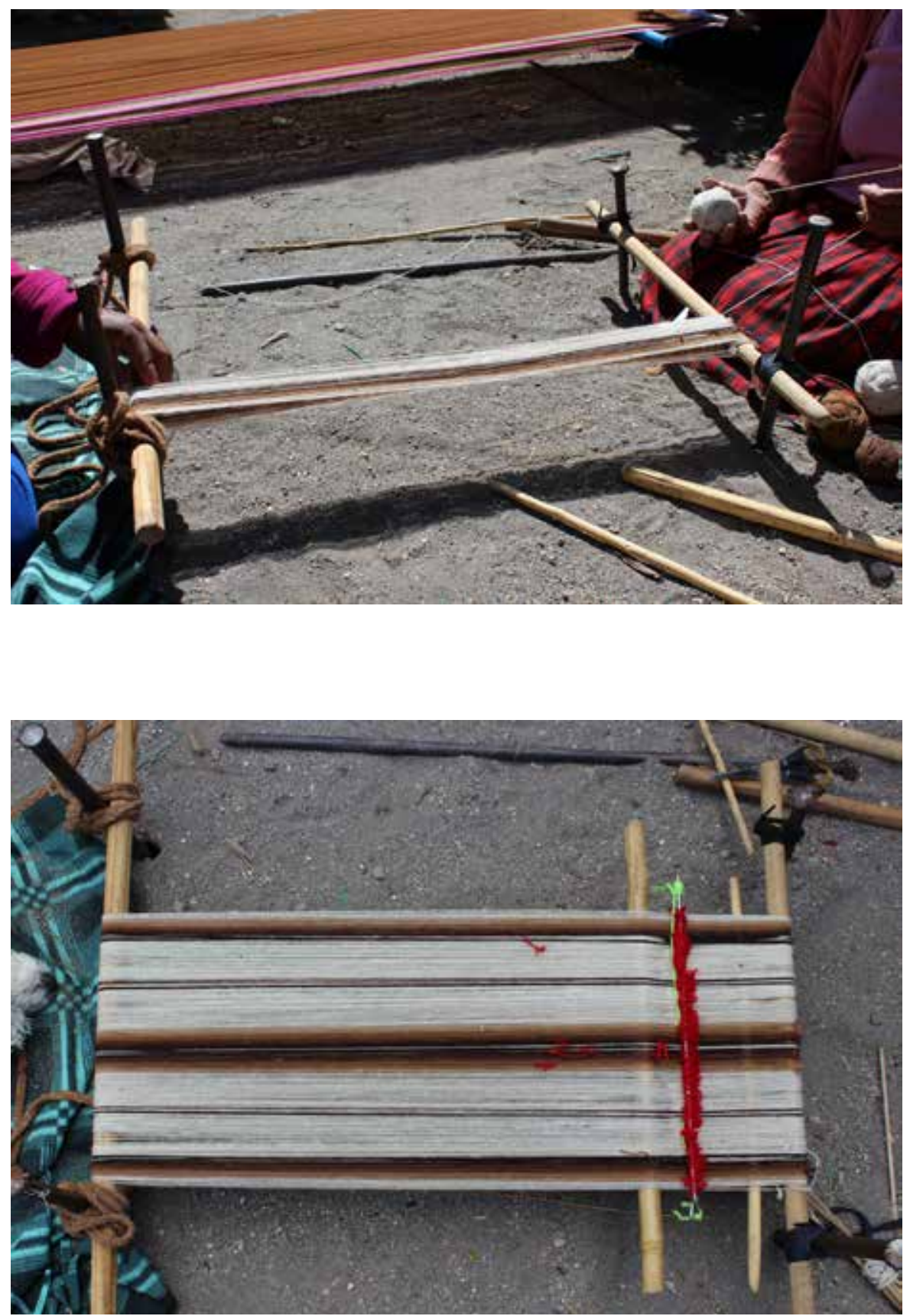

Setenta y una de las setenta y nueve bolsas de Doncellas examinadas por Rolandi de Perrot (1979: 35) combinan variaciones en el listado por urdimbre con listas en peinecillo (o en peine). ${ }^{7}$ Este diseño, formado por pequeñas barras horizontales en tejido llano, se produce alternando hilos de urdimbre de dos o más colores contrastantes (Figuras 1b, 5b, 6b, 8b y 12b). Un ejemplo temprano de peinecillo en los Andes centro sur es una banda estrecha envuelta alrededor de la cabeza de una mujer adulta, que proviene del cementerio de Morro 1, Arica, Chile, y tiene "un fechado posterior a los
Figura 2a. Doña Soria Mamani Challapa comienza a urdir un telar para una bolsa que tejería la autora de este texto. Se nota el cruce o qata formado por los hilos de la urdimbre. Enero de 2017, Isluga, Chile.

Figura 2b. El telar ahora está equipado con una varilla de separación y una barra de hierro para el lizo hecho de hilo rojo. El cruce se encuentra entre estas dos varillas. La urdimbre en el eje central está armada para tejer un diseño que se llama pä chinu y en las listas laterales para tejer peinecillos. 
3800 AP" (Standen, 2003: 184). Está tejida de fibra de camélido, en colores sin teñir, el beige alternando con el marrón (Standen, 2003: Figura 5). A partir de entonces, el peinecillo se estableció en el repertorio textil durante el período Formativo (3700-1500 AP), a medida que el telar llegó a ser más utilizado en los Andes centro sur (Niemeyer y Schiappacasse, 1963: Lámina XX, Figura 6).

Espoueys et al. (1995: 123, nota 6), han sugerido que la práctica de incluir peinecillos en telas tejidas con hilos de camélido "de gran suavidad" en la forma de camisas, bolsas y cintillos podría haber adquirido un aspecto emblemático en la vestimenta de grupos locales cuando la gente de Tiwanaku se puso en contacto con ellos. Agüero (2007: 91) describió un costal del sitio de Pulacayo, Bolivia, encontrado en una cueva con entierro colectivo al este del Salar de Uyuni. Esta bolsa tiene listas laterales que son asimétricas, incorporando peinecillos e hilos transpuestos en el listado por urdimbre, y organizados alrededor de una lista central blanca. Según Agüero, la bolsa es uno de varios textiles hallados en la cueva que comparte las características de los textiles locales de la zona de San Pedro de Atacama, en lugar del resto de los textiles, que muestran rasgos de Tiwanaku.

El análisis de una bolsa ceremonial pequeña pero fina de filiación tiwanaku proveniente de una tumba del cementerio Sobraya en el valle de Azapa, del Período Medio (ca 5001000 DC), indica que también se podrían hacer diseños en peine en un textil listado por trama (Espoueys et al., 1995). ${ }^{8}$ El cuerpo de esta bolsa parece haber sido hecho en una urdimbre circular orientada horizontalmente. El diseño tiene tres ejes verticales y cada uno consiste en una secuencia de listas estrechas incluyendo un peine doble (Espoueys et al., 1995: 115). Se colocó la urdimbre horizontalmente para presentar los ejes del diseño en disposición vertical en imitación de los diseños de peinecillos en el listado por urdimbre. En el caso de esta bolsa, parece que hubo una interacción visual, con una tejedora (o tejedor) tiwanaku enfrentándose al desafío de los textiles locales al producir el mismo efecto visual a través de la manipulación de la trama y no de la urdimbre. Es como si la tejedora dijera "cualquier cosa que puedan hacer por la urdimbre yo puedo hacerla por la trama”.

El uso de peinecillos en el listado por urdimbre había ido ganando terreno; por ejemplo, ya está presente en prendas desenvueltas de los paquetes de momias femeninas del período Intermedio Temprano de la Necrópolis de Paracas en el sur del Perú. Estas prendas se confeccionan a partir de una gran tela rectangular con un borde aplicado a cada lado que no siempre corresponde exactamente a la longitud de la tela. Según Peters y Tomasto-Cagigao (2018: 392-393), los bordes consisten en peinecillos en colores rojo, azul, amarillo, verde y, a veces, marrón púrpura. En las prendas, los bordes sirven para rodear a la mujer. Estos bordes pertenecían a una tradición diferente de aquella a la que respondió la tejedora de la bolsa tiwanaku. Esta otra tradición iba a transmitirse en los períodos preincaicos e incaicos al norte y al sur a lo largo de la espina dorsal de los Andes. En esta, el peinecillo articulaba un diseño generalmente con un eje central y, a veces, con ejes laterales, dividiendo el campo visual de una bolsa en cuatro o más partes.

Debido a que las condiciones para preservar los textiles en los Andes no son tan buenas en las tierras altas como en las áridas regiones costeras e incluso en el desierto de Atacama (Agüero, 2015), hay menos evidencias provenientes de sitios altiplánicos para vislumbrar el desarrollo en el uso de peinecillos en el listado por urdimbre. La supervivencia de un fragmento de una talega o costal atribuido por Arellano López al señorío Mallku en Lípez, Bolivia (2000: 194, Fotografía 28), sugiere que ha habido cierta continuidad formal en la disposición de los peinecillos en tales textiles, que pertenecen al Intermedio tardío (1000 DC-1450 DC), hasta el presente. ${ }^{9}$ Otro fragmento de tela (tal vez de una túnica) proveniente del sitio Chajrapujro $\mathrm{CH}-184$, hecha de lana de camélido, muestra delgadas listas paralelas, "de colores azul y 
rojo sobre marrón oscuro natural" (Arellano López, 2000: 193). La combinación de colores teñidos (rojos y azules en peinecillos y listas angostas) con vellón sin teñir es una característica marcada de las bolsas de Doncellas y también de las talegas de filiación uru-chipaya contemporáneas en Bolivia (Espejo y Arnold, 2014: 320). ${ }^{10}$

Hoy en día, el término que las tejedoras de habla aymara aplican al peinecillo es k'uthu, derivado de k'uthurata, "algo recortado", que Arnold y Espejo (2015: 201) comentan que se relaciona con el corte de papas antes de la siembra o con el acto de reducir el tamaño de la yareta (k'uthunuqaña) para quemar en el fuego las partes blancas que sobresalen, dejando crecer el resto de la planta. El término k’uthu, asociado con la reducción en pequeñas piezas, solo se puede aplicar de manera descriptiva a los diseños textiles prehispánicos porque la idea de cortar en rodajas está asociada con el tipo de acciones que se pueden efectuar mediante el uso de herramientas como cuchillos de metal y tijeras introducidas en los Andes por los comerciantes europeos. En tiempos prehispánicos, ante la ausencia de herramientas de metal que tuvieran filo cortante, las acciones de corte que implica el término k’uthu no habrían tenido una resonancia similar. La gente habría manejado herramientas de piedra y estaría más acostumbrada a combinar acciones de cortar, raspar y golpear. Hasta la década de 1980, antes de que las tijeras se generalizaran en Isluga, las tejedoras guardaban una pieza de vidrio de botella en la tierra junto a una de las estacas del telar clavadas en el suelo. Utilizaban el vidrio tallado como una lasca de obsidiana, para sacar los extremos de la trama que quedaban colgando a medida que avanzaba la tela; la acción era más parecida a la esquila que al corte.

Por el contrario, el término peinecillo, que pertenece a un idioma no nativo, podría relacionarse a los peines prehispánicos conocidos. Dos peines hechos de madera y espinas de cardón acompañaron los restos de un niño con procedencia de la localidad de Doncellas (Bosio et al., 2008-2009: 141). En realidad, no sabemos cómo la gente prehispánica podría haber llamado a lo que ahora se conoce como peinecillo o k’uthu, o si tenían algún nombre para ello.

Espejo y Arnold (2014: 303-304) explican que una tejedora puede utilizar un peinecillo para definir las primeras filas de un tejido y, a menudo también las últimas cuando la tejedora inserta los pases finales de la trama con agujas porque la calada donde se entra la trama se ha vuelto demasiado reducida. Asimismo, advierten que los peinecillos pueden dividirse en diferentes categorías, contando los hilos de urdimbre. Si el conteo es impar (por ejemplo, 3/3) el peinecillo se llama ch'ulla k'uthu y si es par (digamos 4/4) se llama paris k'uthu. Espejo y Arnold (2014: 315) dicen que en la región de Challapata, Bolivia, las dos formas de k'uthu se asocian con talegas utilizadas para almacenar cultivos alimentarios, pero ch'ulla k'uthu se asocia particularmente con el almacenamiento de semillas, y la gente también llama al peinecillo de conteo impar mira kasta ("el grupo que se reproducirá") en referencia al potencial de fertilidad. Un recuento impar se considera incompleto, como si el hilo estuviera esperando a su compañero, mientras que un recuento par está completo "en sí mismo" (Espejo y Arnold, 2014: 310).

Evidentemente, existen variaciones regionales porque normalmente en Isluga los peinecillos no se incorporan en las talegas llamadas wayaqa para guardar quinua molida, o maíz obtenido en los valles de la precordillera chilena o en el mercado boliviano (Figura 3). Tampoco se incorporan peinecillos en pequeñas bolsas llamadas wayuña para conservar semillas de quinua para la siembra. En cambio, las tejedoras los incorporan en otros tejidos como frazadas, cintillos y pequeñas bolsas ceremoniales para llevar hojas de coca (chiuspa). En la ch'uspa de la Figura 4, los hilos del peinecillo tienen un conteo seis de color claro y seis de color oscuro (6/6), o sea un conteo por par (paris). ${ }^{11}$ 
Figura 3. Talega (wayaqa) tejida en 1987 por doña Teodora Flores, Isluga,

Chile. Los bordes están acabados en hilos blancos y negros en una técnica llamada k’anipa.

Figura 4. Bolsa ceremonial para hojas de coca (ch'uspa) tejida por doña Teodora Flores. El peinecillo (k'uthu) que forma el eje central está urdido en pares (6 hilos rojo oscuro y 6 hilos color plomo).
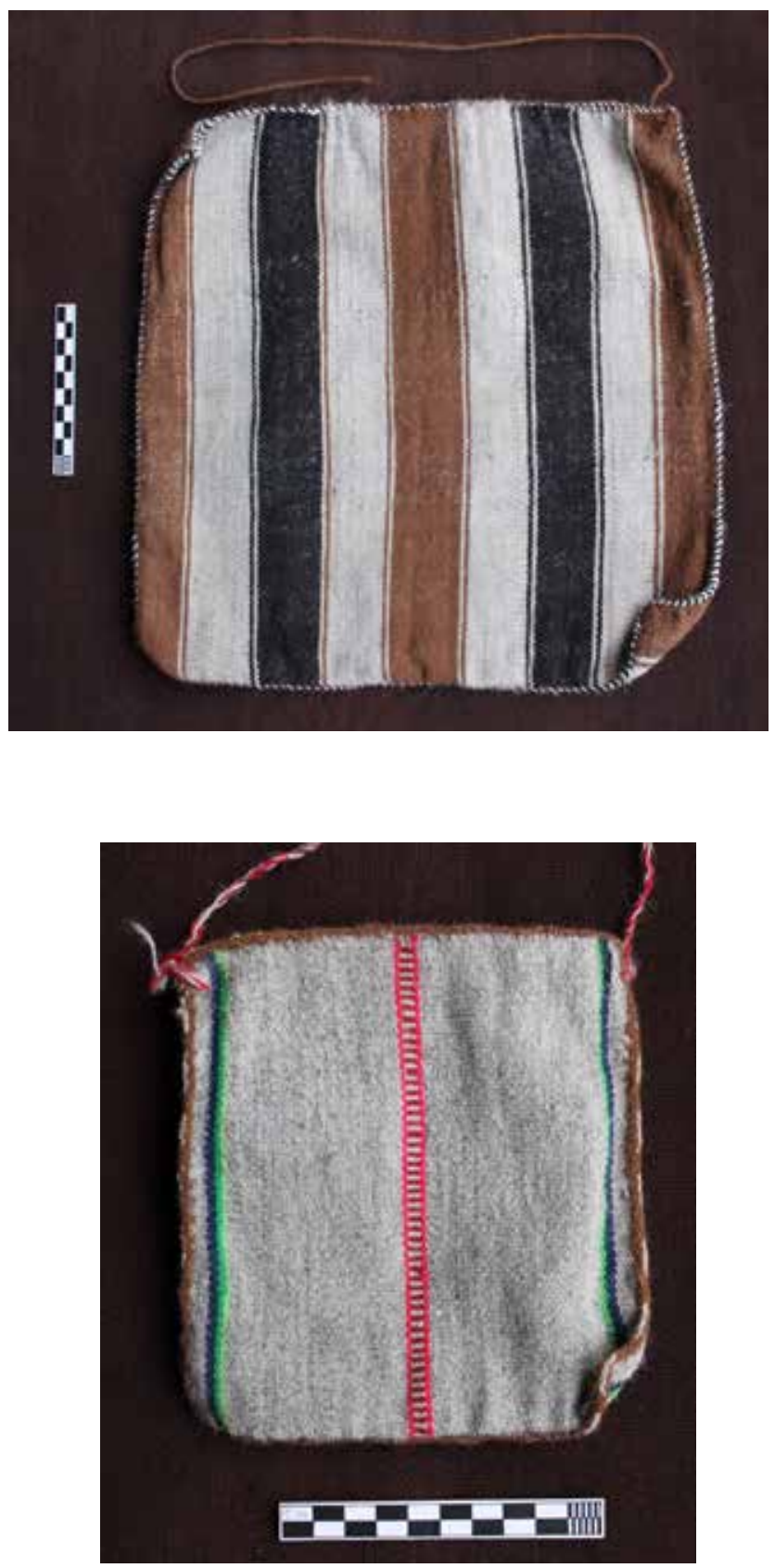

Entonces el uso de una técnica aparentemente simple en un tejido llano, a través de la alternancia de colores contrastantes, puede servir para organizar el diseño de una manera muy versátil. Se puede obtener un efecto de damero doblando el peinecillo, como en la bolsa tiwanaku listada por trama mencionada anteriormente (Espoueys et al., 1995). Un efecto de damero también se presenta en una bolsa de Doncellas, listada por urdimbre; aparece en blanco y negro en dos listas laterales que flanquean una ancha lista central color marrón. ${ }^{12}$

Entre las bolsas de Doncellas hay casos en los cuales los peinecillos y las angostas listas que los acompañan son par e impar a la vez. Rolandi de Perrot (1979: 35) informa que la relación más común entre hilos de color claro y de color oscuro es $3 / 4$, normalmente en rojo y azul. En otras palabras, tres hilos de urdimbre se alternan con cuatro de otro color. En la Figura 5b los tres peinecillos tienen una relación 3/3, 2/2 y 3/3. 
Se nota que estas bolsas se resisten a la categorización como impar o par. Para armar un peinecillo múltiple, es necesario insertar uno o dos hilos de color continuo entre los peinecillos. El resultado es que algunas de las inserciones pueden ser pares, en una ida y vuelta de la urdimbre, o impares, únicamente en la ida. En el caso de la bolsa No 2103 (Figura 1b), hay tres peinecillos en el eje central. El de la izquierda tiene una relación 4/4 en rojo y azul. Está flanqueado a cada lado por un único hilo de color rojo (impar). En el medio, el segundo peinecillo tiene una relación $2 / 2$ en blanco y azul. Está seguido por una ida y vuelta de un hilo rojo (par). El tercer peinecillo tiene una relación $2 / 2$ en azul y rojo, acompañado a la derecha por una ida y vuelta de un hilo azul (par). A cada lado externo de la secuencia de peinecillos, hay tres hilos en blanco (una ida y vuelta más una ida, impar). En total hay treinta hilos de urdimbre en la secuencia y parece que los peinecillos tienen un conteo por par. No obstante, hay hilos de un solo color que irrumpen entre los peinecillos con conteo impar. Estos hilos integran la secuencia. Sin ellos sería imposible multiplicar los peinecillos.
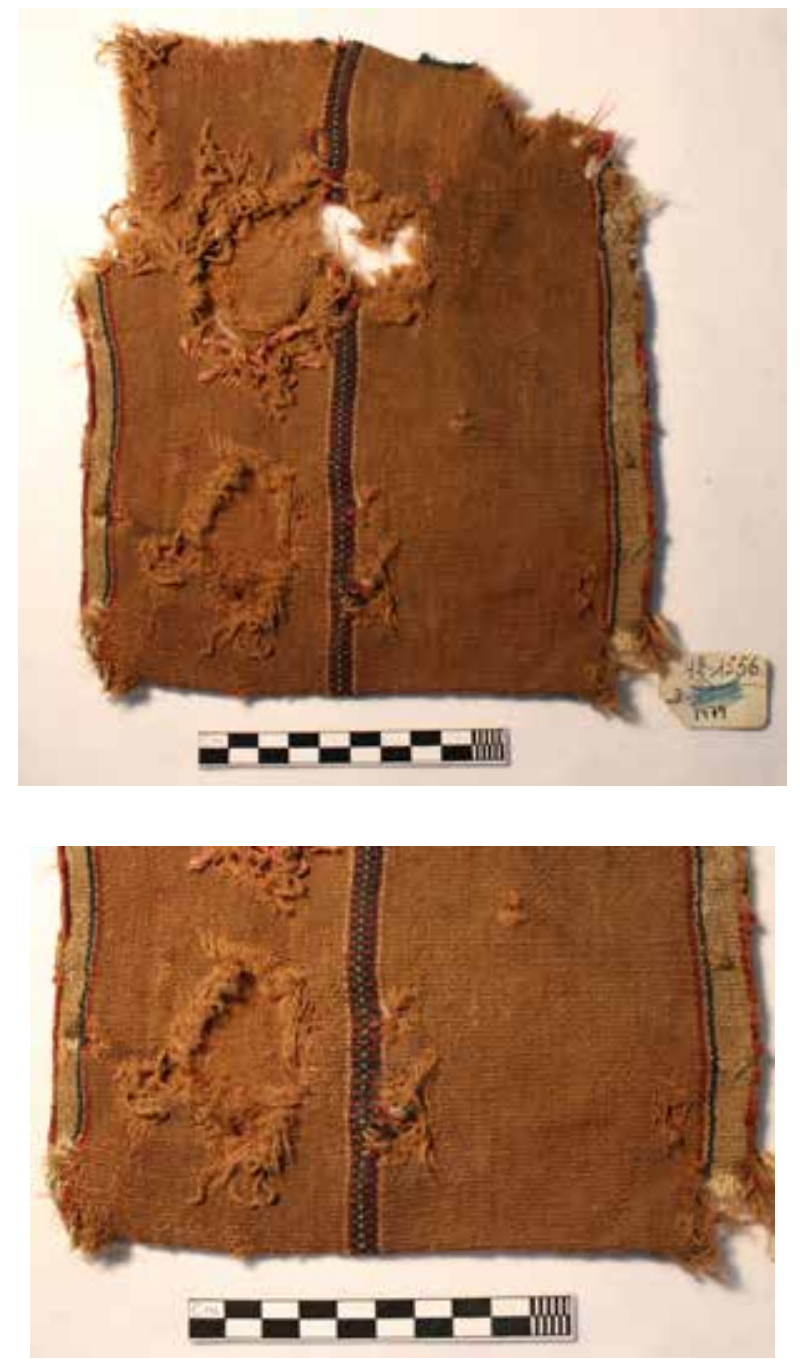

Espejo y Arnold (2014: 316-318) caracterizan a los peinecillos de la talega uru-chipaya mencionada anteriormente por tener un conteo par, mencionando que su lista central está moteada. No explican que el efecto jaspeado se logra mediante la intromisión de hilos de urdimbre impares en un recuento que de otra manera sería un conteo por par, 2/2. Efectos moteados (conocidos como ch'ixch'i entre las tejedoras de habla aymara) eran explotados en tiempos prehispánicos. Agüero (2018: Figuras 3a y 3e) ilustra dos bolsas incaicas provenientes de Doncellas; las cinco listas moteadas del diseño están bordeadas por peinecillos que presentan
Figura sa. Bolsa con diseño simétrico de los enterratorios de Doncellas, № 1479 , 42.1556 (Museo Arqueológico "Dr. Eduardo Casanova", Centro Universitario Tilcara, Facultad de Filosofía y Letras, Universidad de Buenos Aires).

Figura 5b. Detalle de la bolsa en la Figura sa con tres peinecillos en rojo, azul y blanco formando el eje central del diseño con conteo impar y par $(3 / 3,2 / 2$, 3/3). 
Figura 6a. Bolsa con diseño simétrico de los enterratorios de Doncellas, № 1477 , 41.507 (Museo Arqueológico “Dr. Eduardo Casanova", Centro Universitario Tilcara, Facultad de Filosofía y Letras, Universidad de Buenos Aires).

Figura 6b. En la lista blanca deteriorada en la parte inferior de la bolsa, la trama múltiple es visible en una secuencia de un hilo bicolor y dos hilos de color marrón claro. barras horizontales de blanco y negro. La combinación de recuentos impares y pares en un peinecillo problematiza la proyección de las conceptualizaciones actuales basadas en una dicotomía entre dos sistemas de contar los hilos de urdimbre.

Las bolsas de Doncellas varían en proporción y tal vez no todas servían para almacenar alimentos. Algunas son más largas que anchas de manera significativa. Aparte de las bolsas de estilo inca, que están provistas de una manija, las bolsas consideradas aquí tienen un hilo para amarrar la parte superior (Figura 6a). En su condición actual, sin embargo, no se sabe cuáles eran los contenidos y no es posible relacionar los detalles de los peinecillos y otras listas con el papel que desempeñaban las bolsas en la vida cotidiana del propietario.
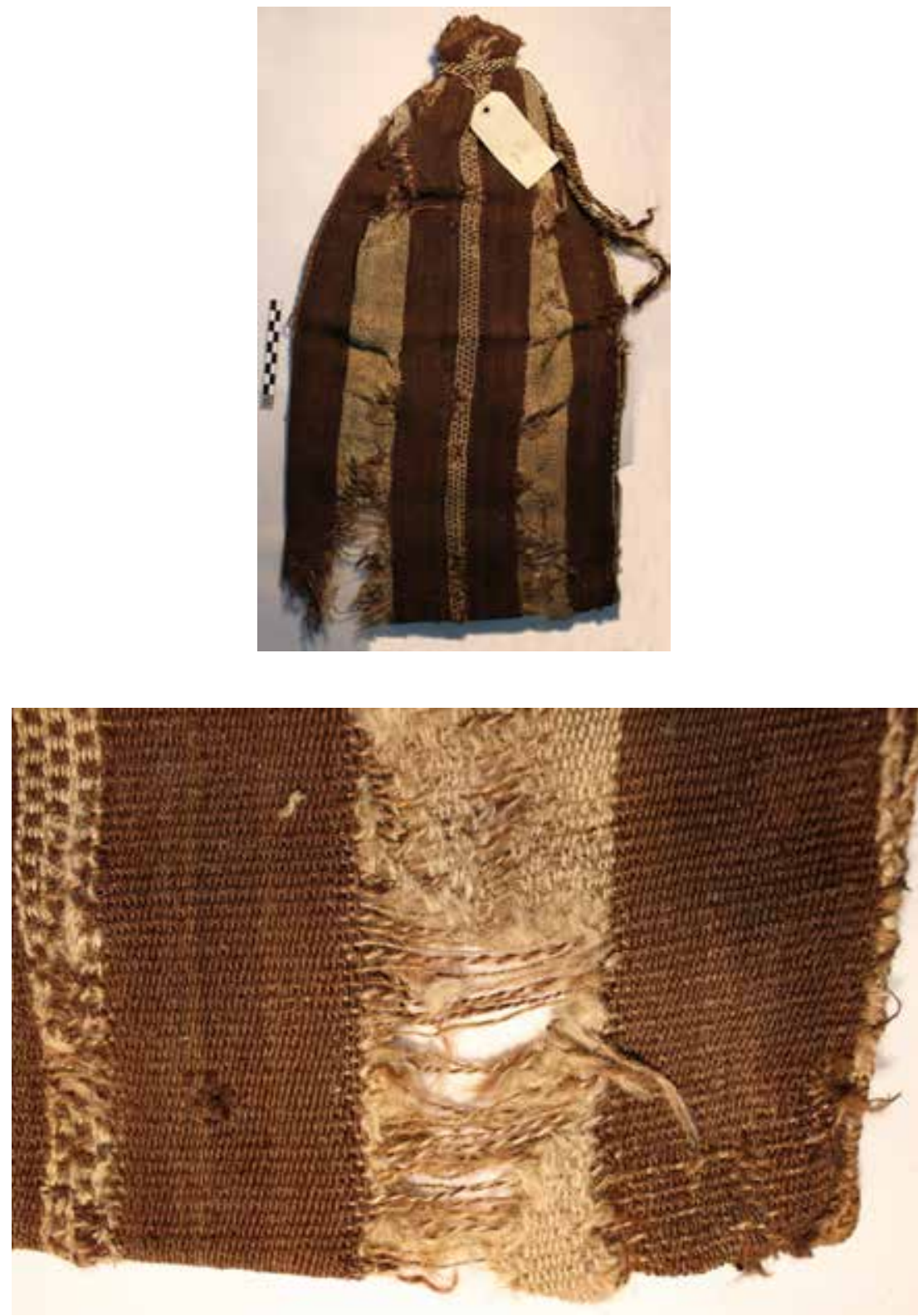

\section{Vellón, la belleza de la materia prima}

Por lo tanto, surge una pregunta sobre el problema de cómo se legitimó la sabiduría en el pasado en relación a la experiencia estética de tejer. Bugallo (2010: 86) ha considerado cómo la elaboración de retablos en la Puna jujeña tiene lugar dentro de 
un "universo productivo", en el que se comparten conocimientos. Es decir, hay una comprensión colectiva de la que germina la eficacia simbólica (Bugallo, 2010: 102). Al contemplar los paralelismos etnográficos por la luz que puedan arrojar sobre el pasado, es importante no rechazarlos totalmente por estar fuera de control. Lo que quisiera hacer aquí es considerar las prácticas de hilar y tejer, teniendo en cuenta los gestos o las acciones corporales necesarios para procesar el vellón y los hilos. Los procedimientos y elecciones que la gente de Doncellas adoptó en el pasado al realizar estas acciones se corresponden a veces con los métodos contemporáneos que he presenciado y/o practicado en Isluga, pero otras veces no. Existen vasijas zoomorfas de Doncellas y otras comunidades de la Puna con la forma de camélidos con un hueco en el lomo para líquidos o grasa (Zaburlín, 2016). Si estos recipientes se utilizaron para hacer libaciones como hace la gente hasta hoy en día, tal vez los pastores de Doncellas hicieron súplicas rituales para pedir no solo la multiplicación de sus llamas, sino también el aumento en sus rendimientos de vellón. Tales actos pertenecerían al universo productivo de pastorear y tejer en Doncellas.

Las propiedades del vellón también proporcionan un punto de partida para explorar las preferencias estéticas de la gente de Doncellas. Los colores de vellón utilizados en la urdimbre de las bolsas son marrón claro, marrón medio, marrón oscuro rico como el chocolate (que es para invocar un anacronismo) y negro o casi negro. El blanco se utilizaba en cantidades menores. Parece que el gris o plomo solo estaba disponible en pequeñas cantidades (Figuras la y b). ${ }^{13}$ También hay un color blanquecino que Rolandi de Perrot (1979: 38) llama arena. Si las túnicas encontradas en los enterratorios de Doncellas, muchas de las cuales son de los colores más oscuros, fuesen contemporáneas de las bolsas, significaría que había un gran número de llamas oscuras en los rebaños. Las llamas blancas parecen haber sido relativamente más escasas. El hecho de que la gente utilizaba los colores de vellón a su disposición para fines específicos, manteniendo el blanco para las bolsas y el marrón oscuro para las túnicas y algunas listas en las bolsas, está en consonancia con las prácticas de hoy.

En Isluga, para preparar un vellón antes de hilar, una persona lo sujeta debajo del brazo derecho y lo estira con las puntas de los mechones hacia arriba. La hilandera saca las puntas enmarañadas y extrae los pelos gruesos. En el proceso, los pequeños pedazos de vegetación atrapados en el vellón caen al suelo. El objetivo es limpiar el vellón estirándolo en una masa diáfana sin convertirlo en pedazos. Ahora el vellón está lleno de aire y ocupa mucho más espacio que antes. Normalmente la hilandera se sienta y coloca el vellón sobre su regazo. Ella lo da vuelta para asegurarse de que no queden más puntas enmarañadas o pelos gruesos. Luego lo saca en un rollo largo y suave, que envuelve alrededor de su muñeca izquierda (Dransart, 2002: 110). En esta condición, el vellón se asocia con un reino de cualidades táctiles relacionadas con las propiedades granulares y fluidas (Martínez, 1980: 88, 100; Dransart, 1995: 231-236, 2002: 104; Arnold y Yapita, 1998: 100; Bugallo, 2016: 151-154). De acuerdo con una comprensión del cosmos a lo largo de los Andes, los fenómenos terrenales son paralelos a los celestes. En Isluga, el carácter granular y fluido del vellón tiene su contraparte en la vía láctea, que se llama jawira o "río". Durante mis estadías de los años 1980 y 1990 en Isluga, escuché a las tejedoras susurrar una invocación a la Wirjina (o Wirjin Tayka), el nombre con el cual veneran a la Pachamama, al clavar las estacas de hierro del telar en el suelo, golpeándolas con una piedra. Este pequeño ritual cotidiano rendía respeto a la tierra que nutre los pastos comidos por los camélidos y al vellón que crece de su cuerpo. También constituyó una solicitud para un resultado exitoso en el tejido. Con esta evocación de un contexto específico e histórico de pastoreo en un mundo relacional, deseo concebir cómo las personas utilizaron los materiales obtenidos de su entorno en un universo lleno de significados. 
Las bolsas mismas de Doncellas aportan pistas. Según Rolandi de Perrot (1979: 45, 64-66), la mayoría de los textiles de Doncellas tiene una densidad de entre 20 y 40 hilos por $10 \mathrm{~mm}$ en la urdimbre y de entre 5 y 10 hilos por $10 \mathrm{~mm}$ en la trama. Esta proporción es promedio en textiles hechos de fibra de camélido. Los promedios sugieren que el tejido se ajustó cuidadosamente a las necesidades de fabricar recipientes para ser utilizados en la vida diaria. La autora notó una diferencia con los tejidos de Tastil, donde había una distribución más bimodal en la densidad del tejido; los textiles de tejido llano allí tendían a tener un menor recuento de urdimbre y trama que los textiles cuyos diseños incluían hilos transpuestos en la urdimbre, donde el recuento es más alto. Rolandi de Perrot (1979: 45) comentó que entre las bolsas de Doncellas hay algunos ejemplares de tejido llano con recuentos altos de hasta 64 hilos por $10 \mathrm{~mm}$ en la urdimbre y de 14 en la trama, mientras que los recuentos entre las telas con hilos de urdimbre transpuesta varían desde 26 a 38 hilos por $10 \mathrm{~mm}$ en la urdimbre y desde 6 a 8 hilos en la trama. Parece que las tejedoras (o tejedores) respetaron los materiales proporcionados por su cosmos y prepararon casi todas las bolsas con el mayor esmero.

\section{Hilando urdimbre y trama}

En los Andes centro sur, hay una tradición de emplear dos cabos en el hilo destinado a servir como urdimbre en un tejido. Normalmente la urdimbre se hila en el sentido de las agujas del reloj (en Z) y se dobla en sentido contrario a las agujas del reloj (en S). Este hilo debe tener una superficie muy lisa, de lo contrario, los elementos se pegarían cuando la tejedora intente levantar una serie de hilos de urdimbre a través del cruce (qata) y bajar la otra serie, antes de insertar la trama. Para tejer diseños elaborados, la tejedora tiene que transferir el cruce, sosteniéndolo con los dedos de la mano izquierda, mientras que recoge los hilos que necesita con los dedos de la mano derecha. Esta manera de tejer exige un alto grado de destreza manual (Dransart, 2002: 242-243; ver Zorn 1992: 162, Figura 3).

En Isluga, como trabajo femenino, las tareas de hilar y torcer se realizan en un huso de mano. ${ }^{14}$ Para hilar, la hilandera envuelve el vellón alrededor de su muñeca izquierda y lo extrae con la mano derecha, girando la varilla del huso con el pulgar y el dedo medio de la mano derecha. Para torcer (o doblar), enrolla dos cabos de hilo en un ovillo y lo sujeta con un prendedor en su hombro izquierdo. Torciendo la punta de los dos cabos alrededor de la varilla del huso, sostiene la varilla entre las palmas extendidas de ambas manos, moviendo rápidamente la palma derecha contra la izquierda, empujando el huso lejos de su cuerpo y dejándolo caer libremente (Dransart, 2002: 112). La acción repetida de frotar la varilla del huso contra las palmas de las manos hace que duelan, especialmente en los bordes inferiores, la aprendiz debe soportarlo hasta que sus manos se habitúen. Hasta que la aprendiz no haya dominado este control sobre el huso, en mi experiencia, su hilo carecerá de la calidad uniforme requerida por la urdimbre (Figura 7).

Según Rolandi de Perrot (1979: 28) en la mayoría de las bolsas de Doncellas se utilizó una urdimbre hecha de dos cabos, hilada en $\mathrm{Z}$ y torcida en $\mathrm{S}$, pero en veintidós de las bolsas hay una combinación de hilos simples y torcidos en la misma tela. Se utilizó una urdimbre simple en otras nueve bolsas. El efecto en la tela acabada es por lo tanto siempre el mismo; la dirección final en el hilo es en S. La urdimbre de un cabo simple debe haber sido planeada por adelantado y la hilandera la habría hilado en sentido contrario a las agujas del reloj.

Entre las bolsas de Doncellas, casi todos los hilos de trama están torcidos de dos cabos (Rolandi de Perrot, 1979: 28). La tensión de la torsión es floja en comparación con el 
doblado fuerte de los hilos de urdimbre. En un tejido listado por urdimbre, la trama debe ser más flexible y la torsión mucho más suelta que en la urdimbre. Por lo tanto, el diámetro de la trama es más variable que en el caso de los hilos de urdimbre.

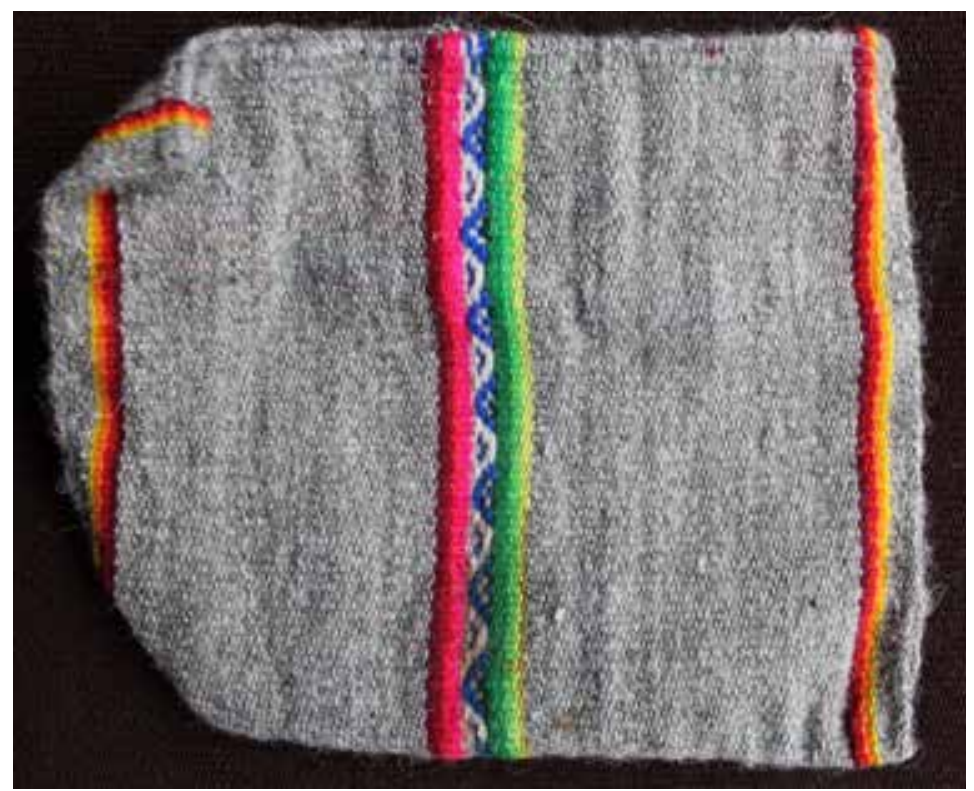

Una bolsa casi dos veces más larga que ancha está tejida en tejido llano listado por urdimbre en los colores naturales, marrón oscuro y blanco (Figura 6a). ${ }^{15}$ Un peinecillo múltiple forma el eje central del diseño; cada peinecillo tiene un conteo $3 / 3$ (tres hilos blancos y tres hilos marrones). Las listas de color blanco continuo se urdían en pares a los lados externos de la secuencia, pero las dos internas se urdían con tres hilos (una ida y vuelta más una ida). Donde los hilos de la urdimbre están desgastados cerca de la parte inferior de la bolsa, se nota una secuencia en los hilos utilizados en la trama: un hilo bicolor es seguido por dos de color marrón claro (Figura 6b).

Rolandi de Perrot (1979: 28) detectó tal uso de trama múltiple en veinticinco bolsas; en el caso de doce ejemplos se alternaron dos hilos de trama, en los otros trece ejemplos, la tejedora manipuló tres, cuatro o cinco hilos de trama. Agüero (2018) señala que esta multiplicación demuestra una similitud significativa con los textiles de la cuenca del Salar de Atacama y del río Loa en Chile. Al utilizar una trama múltiple, las tejedoras pudieron equilibrar las diferencias en el diámetro del hilo para producir una superficie lisa en la que los hilos de urdimbre cubrían bien la trama.

La bolsa aproximadamente cuatro veces más larga que ancha de la Figura 8 muestra el uso de una trama múltiple. ${ }^{16} \mathrm{El}$ diseño asimétrico de la bolsa presenta listas de urdimbre contrapuestas de marrón muy oscuro y blanco. Hay un eje central con peinecillo; en una relación $3 / 3$, el blanco se combina con marrón oscuro, cambiando al rojo con marrón oscuro. Aunque la urdimbre oculta la trama en una tela con faz de urdimbre, en esta bolsa la trama es consistentemente bicromática. En su mayoría los hilos de la trama constan de un cabo blanco y el otro marrón muy oscuro para que coincidan con los colores utilizados en el listado de urdimbre (Figura 8b). En la parte inferior de la bolsa, se intercala un hilo bicolor blanco y marrón claro entre el otro hilo de trama.

La preferencia por utilizar una trama bicromática es característica de las talegas y los sacos que se tejen hoy en Isluga (Figura 3). Las tejedoras explican que la trama debe estar entrelazada con urdimbre de colores sucesivos claros y oscuros y que una trama bicromática ayuda a mantener el contraste entre los colores claros y oscuros. Esta práctica parece haberse ya establecido cuando fueron tejidas las bolsas de Doncellas.
Figura 7. Bolsa pequeña para coca (wistalla) urdida por doña Soria Mamani Challapa y tejida por la autora. La urdimbre y la trama de color plomo también fueron hiladas y torcidas por la autora. 
Figura 8a. Bolsa con una disposición de color asimétrica de los enterratorios de Doncellas, № 1487, 42.2507 .

Museo Arqueológico "Dr. Eduardo Casanova", Centro Universitario Tilcara, Facultad de Filosofía y Letras, Universidad de Buenos Aires.

Figura 8b. Detalle de la bolsa de la Figura 8a, donde se nota el uso de un hilo bicromático en la trama y, del lado derecho de la foto, un hilo teñido de rojo en el zurcido.
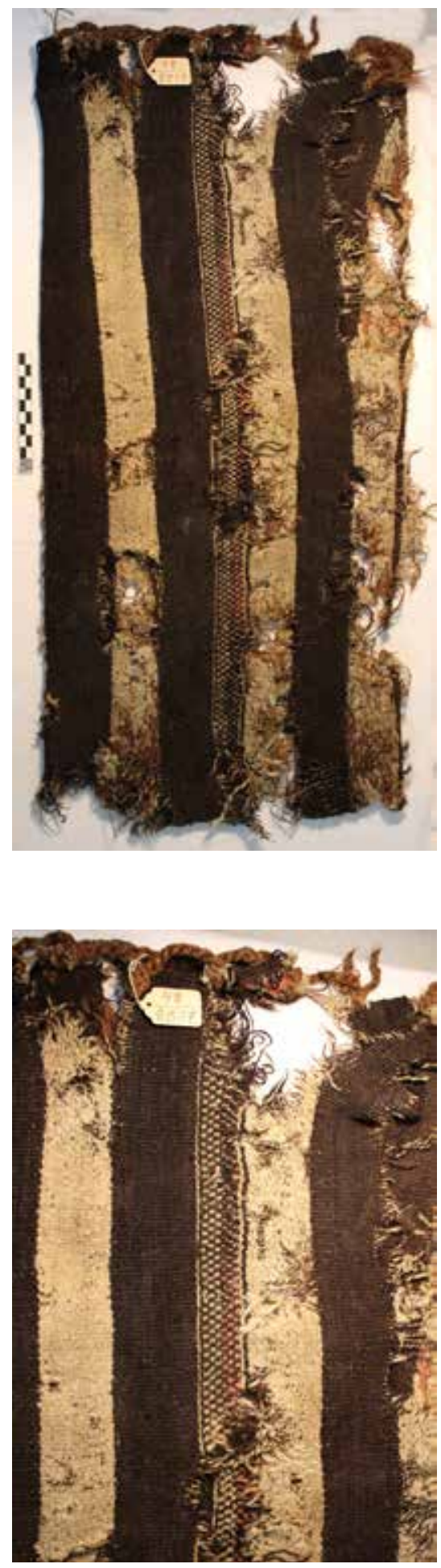
Si cada hilo de la urdimbre en un tejido faz de urdimbre tiene una superficie consistentemente lisa hace resaltar la estructura del tejido con gran claridad. Las tejedoras de Isluga lo describirían como "pelado" o qara (Dransart, 2002: 115, 243). Este término es de gran elogio en reconocimiento de la habilidad de la hilandera/tejedora. La preferencia en Isluga por un tejido llano que consiste en una infinidad de pequeños "granos" que son claramente visibles tiene raíces profundas, porque la predilección también es evidente en las bolsas de Doncellas. En este sentido, es llamativo el término "granicillo", que Rolandi de Perrot (1979: 37) dice que se aplica a los peinecillos particularmente angostos.

Los hilos utilizados para zurcir las bolsas de Doncellas, sin embargo, son diferentes. Pueden ser variables e incluso vellosos. Se usaron al menos tres hilos diferentes en el zurcido en la bolsa de la Figura 8, incluido uno teñido de rojo e hilado de dos cabos en Z, torcido en S y doblado de nuevo en Z. El zurcido se presenta en tejido llano pero "casi siempre en forma muy desprolija" (Rolandi de Perrot, 1979: 32). Hay un contraste sorprendente entre las áreas de zurcido y la textura cuidadosamente elaborada de la tela original (Figura 1b). Parece que la estrategia de no hacer que el zurcido se vea como el tejido original fue intencional.

\section{Transposiciones: desviando el sendero de la urdimbre}

Normalmente en un tejido, la urdimbre sigue un curso unidireccional directamente desde un extremo al otro del telar. ${ }^{17}$ No obstante, se puede urdir hilos de diferentes colores en un peinecillo en combinación con diseños complejos basados en la manipulación de la urdimbre. Hay un ejemplo en la bolsa $\mathrm{N}^{\circ} 43.1385$, donde el eje central consiste en un peinecillo de colores rojo y verde (en relación $4 / 4$ y $3 / 3) .{ }^{18}$ El peinecillo está flanqueado en ambos lados por una lista blanca que consta de ocho hilos en cada lado. Con los pases sucesivos de la trama, algunos hilos blancos cruzan los hilos del peinecillo hasta encontrarse en el medio del eje y vuelven a los lados para hacer un diseño de rombos blancos sobre un fondo de pequeñas barras rojas y verdes (Rolandi de Perrot, 1979: 37).

Cuando un hilo de urdimbre cruza a otro, Emery (1980: 188) llama transposed-warp weave a la interacción. Observó sobre esta técnica:

En ciertas estructuras de (...) tejido llano (...) los hilos de la urdimbre seleccionados se desvían en algunos puntos y se mueven, por una distancia, en trayectorias diagonales. Están entrelazados por los pasos regulares de los elementos de trama, que al mismo tiempo entrelazan otros hilos de la urdimbre cuyos caminos se cruzan. (...) Como ciertos hilos se mueven en diagonal en la tela, los que atraviesan hacen una ligera digresión, unos cuantos a la vez, para pasar, junto con la trama regular, a través de la parte de cada cruce regular que está formado por los hilos de la urdimbre que se están procediendo en cursos diagonales. (1980: 180, traducción mía)

Debido a la secuencia de los colores en las costuras laterales de la bolsa № 43.1385 , esta puede haber sido tejida durante el período de contacto incaico en la región. El verde es un color excepcional entre los textiles de Doncellas (Rolandi de Perrot, 1979: 30), pero el diseño de la bolsa con transposed-warp weave se puede comparar con la descripción de Agüero (2018), quien explica que el uso de blanco, rojo y azul en el tejido de urdimbre transpuesta es característico de los pueblos de Atacama en un momento de presencia incaica (ver, en particular, una túnica con rombos delineados en blanco en Agüero, 2018: Figura 4k). En el extremo norte de Chile y en el sur de Perú, existen textiles con otras características listas angostas de peinecillo en rojo y blanco, que se dividen para formar rombos (Figura 9). Los ejemplos peruanos son de un estilo inca regional, que tal vez se originó en el área circum-Titicaca (Dransart, 2014: 226-228). 
Figura 9. Detalle de un pañuelo de Arica, Chile, listado por urdimbre en listas de tejido Ilano, peinecillos contados en pares y rombos formados a partir de la transposición de la urdimbre. № 7003 , de la tumba 27, sitio Playa Miller 4, Museo Universidad de Tarapaca, San Miguel de Azapa.

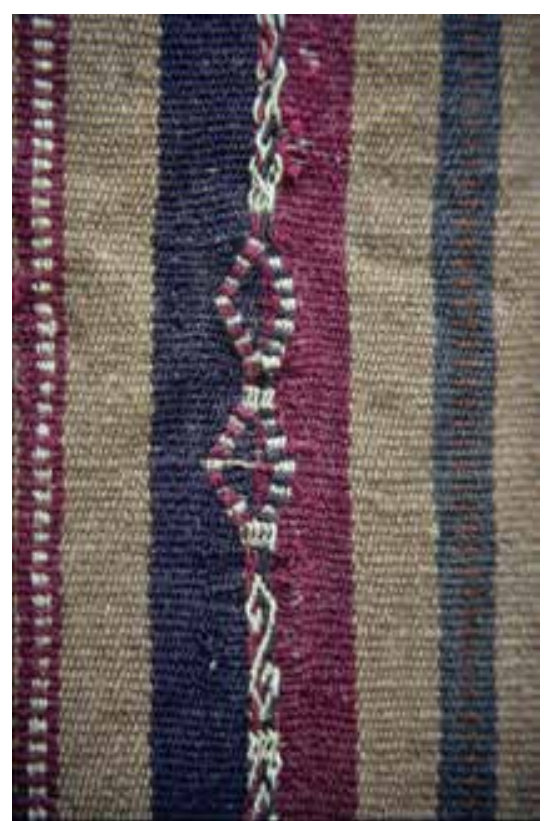

En el caso de Doncellas, transposed-warp weave se produce también sin el uso del peinecillo como principio organizador (Figura 10). ${ }^{19}$ El diseño consta de un eje central y dos listas laterales; las tres están dispuestas alrededor de su propio eje interno de color rojo (Rolandi de Perrot, 1979: 38). Se separan por listas de un solo color no teñido: blanco en los bordes exteriores y marrón adentro. Los colores empleados en las listas de diseño son azul, rojo y blanco, aunque a veces el rojo está algo descolorido. La bolsa está tejida completamente en tejido llano y se crea el diseño con la transposición de los hilos azul y blanco.

Figura 10a. Detalle de la parte inferior de una bolsa con diseño simétrico (a excepción de la omisión de una lista angosta azul oscuro a la izquierda del eje central) de los enterratorios de Doncellas. № 1606 (Museo Arqueológico "Dr. Eduardo Casanova", Centro Universitario Tilcara, Facultad de Filosofía y Letras, Universidad de Buenos Aires).

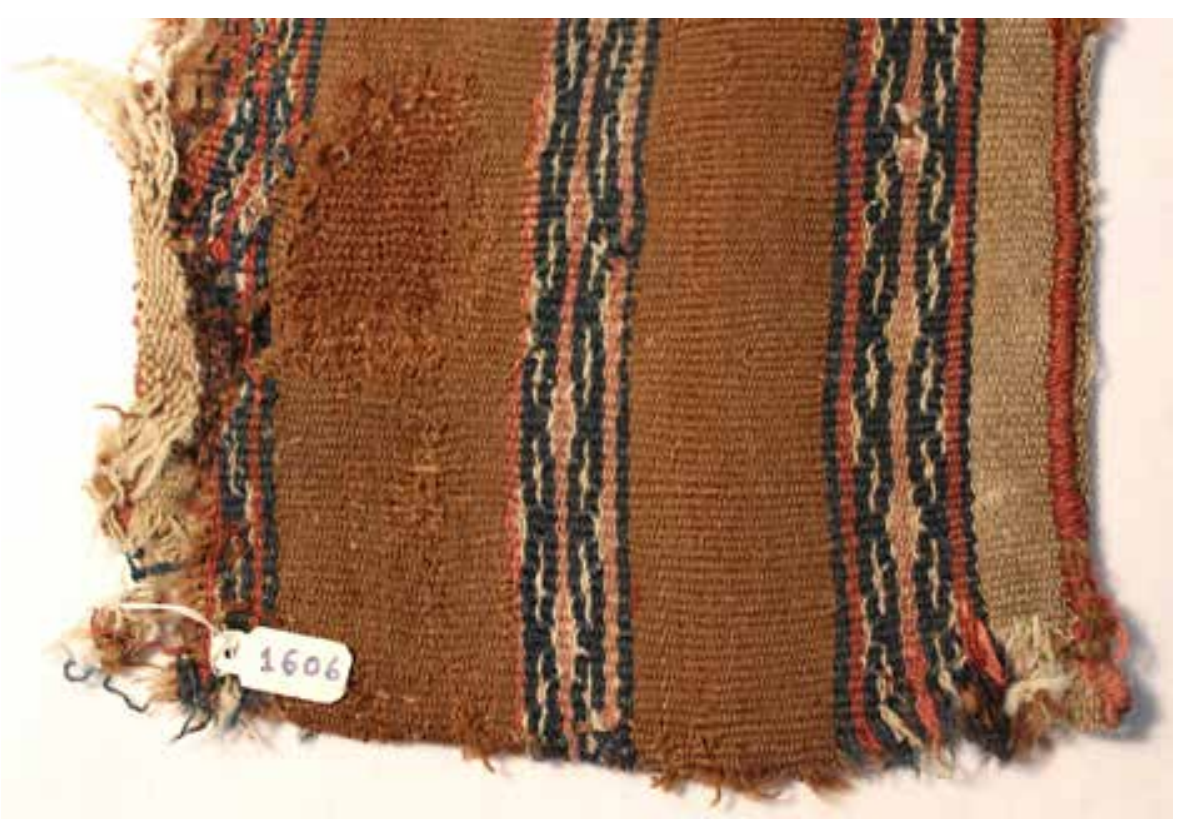




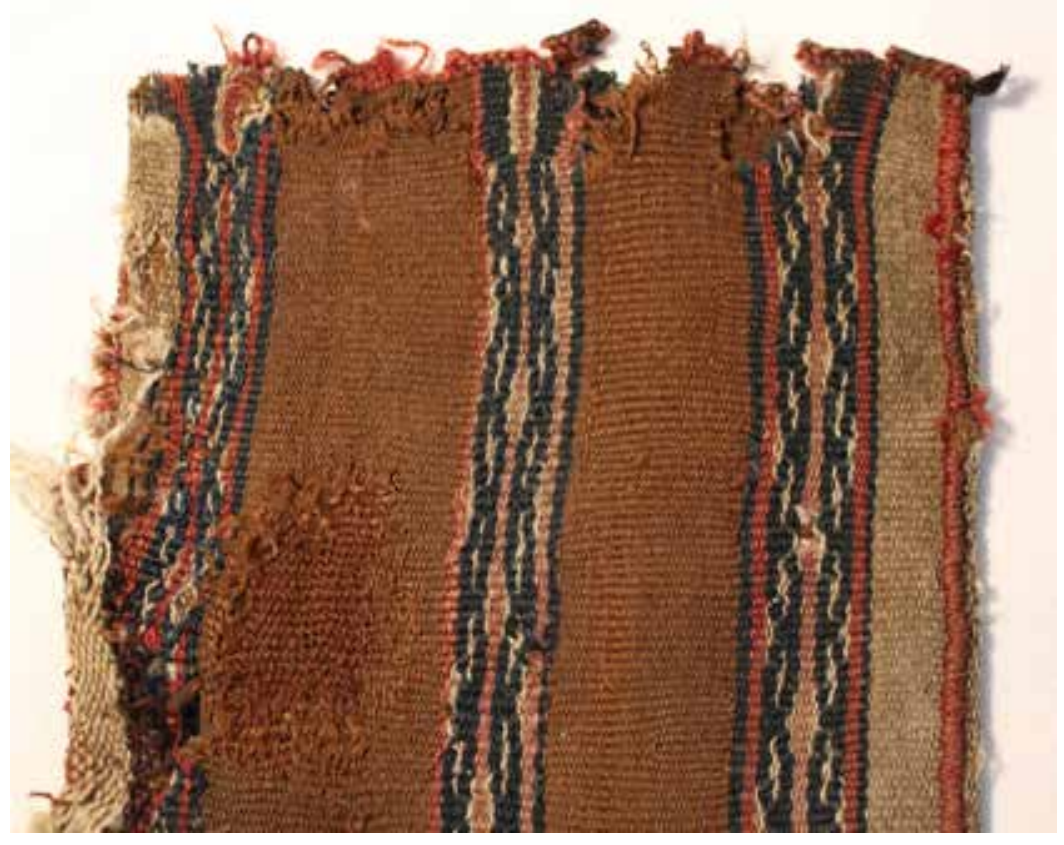

Transposed-warp weave está particularmente asociado con los tejidos de los tiempos prehispánicos tardíos en los Andes centro sur. Sin embargo, a veces las tejedoras contemporáneas transponen hilos de urdimbre para convertir un peinecillo en líneas verticales de un color entero (Figuras 11a y b). Tales listas verticales también se hallan en un textil de Tastil. Se encuentran al lado del orillo al final de la tela en una lista que consiste en zigzags formados por la transposición de los hilos de urdimbre (Rolandi de Perrot, 1973: lámina 17). ${ }^{20}$

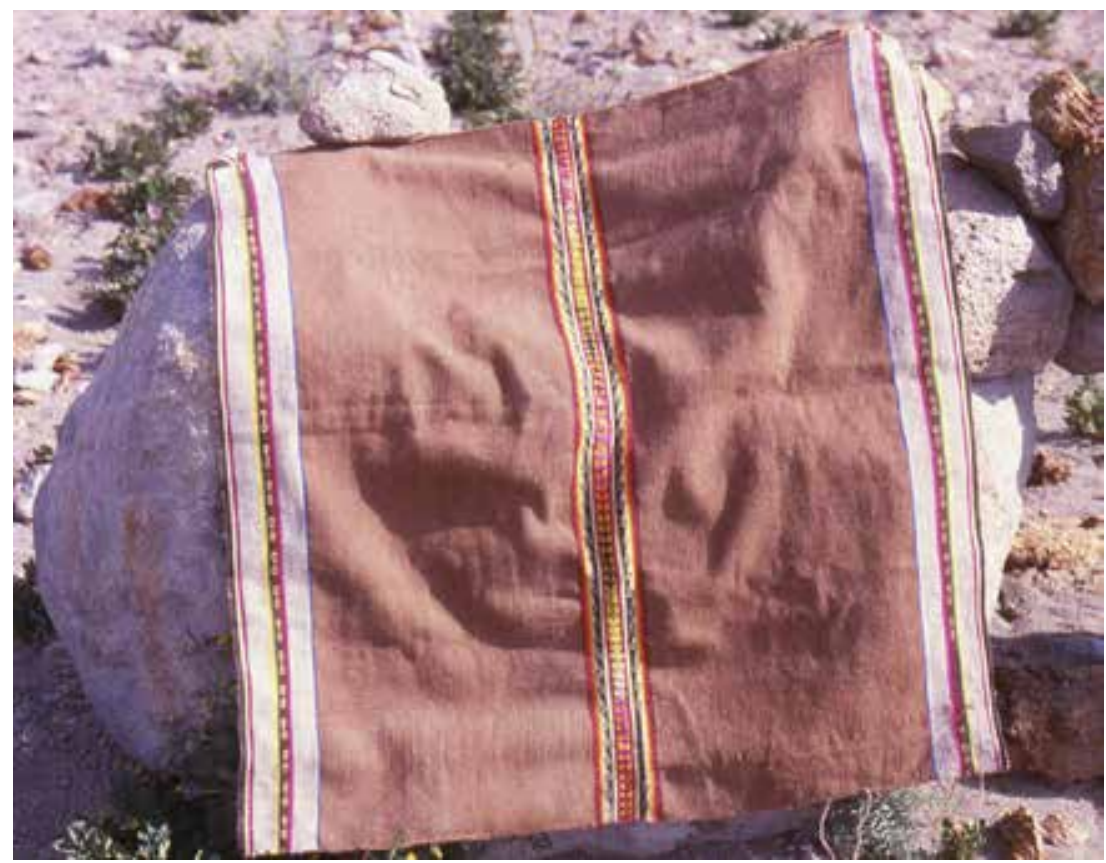

Figura 10b. Detalle de la parte superior de la bolsa de la Figura 10a; se notan las listas angostas de color entero en lugar de peinecillos en la abertura de la bolsa.
Figura 11a. Manta para cargar (awayu) tejida por doña Soria Mamani Challapa para su hija en 1989. La foto fue tomada cuando la tejedora había cosido las dos telas del awayu y estaba terminando las puntas sueltas. 
Figura 11b. Detalle de la costura central de la Figura 11a; en la parte inferior de la foto se nota la transposición de los hilos de la urdimbre en la creación de listas enteras en vez de peinecillos.

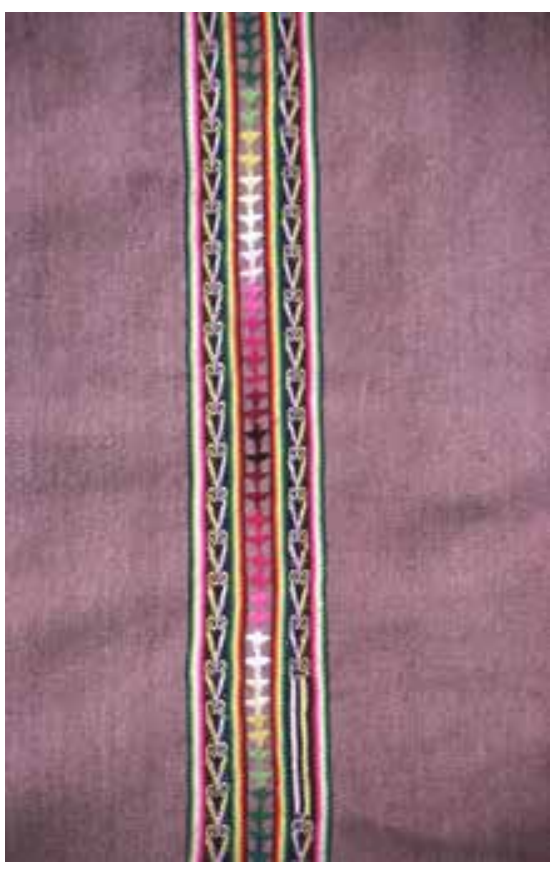

\section{Caracoles: perturbando el sendero de la trama}

En los textiles listados por urdimbre, el objetivo de las tejedoras es mantener la trama en ángulo recto con la urdimbre. De no hacerlo, al insertar la trama es difícil mantener una tensión adecuada. La tarea se ha simplificado mucho en los últimos tiempos porque las tejedoras ahora compran mangos de escoba trabajados industrialmente que sirven como los palos lejanos y cercanos del telar (Figuras $2 \mathrm{a}$ y b). Estos tienen un diámetro uniforme y los hilos de urdimbre son, en consecuencia, de la misma longitud con más precisión. En las décadas de los ochenta y noventa, he observado a los varones de Isluga fabricar las partes del telar de varas obtenidas de árboles en los valles de la precordillera. Mojaban el palo y lo raspaban con un trozo de botella de vidrio como raspador, hasta lograr un acabado liso. En el pasado, podemos suponer que la gente habría utilizado herramientas líticas para tal tarea.

Si los palos del telar no tienen un diámetro constante, un lado de la tela se vuelve gradualmente más alto que el otro y la tejedora debe insertar hilos de trama parciales para compensar. La trama adicional tiene que doblarse en otro paso hacia el lado de donde vino. Las tejedoras de Isluga denominan a tal giro de la trama qiqa o caracol. Los caracoles causan una perturbación en el efecto regular en el entrelazado de la urdimbre y la trama, pero ocurren con frecuencia en los textiles de Doncellas. Hay, por ejemplo, caracoles insertados en la trama en la bolsa No 1606 (Figuras 10a y b). La desviación en la urdimbre se acompaña de perturbaciones en la trama. En Isluga, las tejedoras rompen la trama donde gira el caracol e insertan las puntas junto con los siguientes pases de trama, en diferentes direcciones. Las tejedoras de Doncellas a veces hacían esto, pero en otras ocasiones dejaban el caracol como un simple giro espiral en la tela.

Este proceso dinámico causado por el remolino en la trama se hace eco curiosamente en el río celeste, la vía láctea. Los científicos han demostrado que este sufrió una perturbación con el resultado de que "la distribución por fase y espacio contiene diferentes subestructuras con diversas morfologías, como caracoles y crestas, cuando se combinan las coordenadas espaciales y de velocidad" (Antoja et al., 2018, traducción mía). Cabe señalar que una galaxia y una tela son ambas formas planas.

Otra razón para ajustar la trama aparece en la bolsa de la Figura 12a, que es notable por la inclusión en el diseño de listas amarillas muy estrechas. ${ }^{21}$ La urdimbre en la lista 
marrón oscura tiene un diámetro más fino que los otros hilos, y la tejedora tuvo que insertar varios caracoles hasta el límite entre la angosta lista roja y la lista más ancha de color castaño (Figura 12b). La tejedora también tuvo que resolver otro tipo de problema porque en varios lugares los hilos de urdimbre (rojo y azul) parecían haberse roto y las puntas rotas se insertaron junto con los pases de la trama.
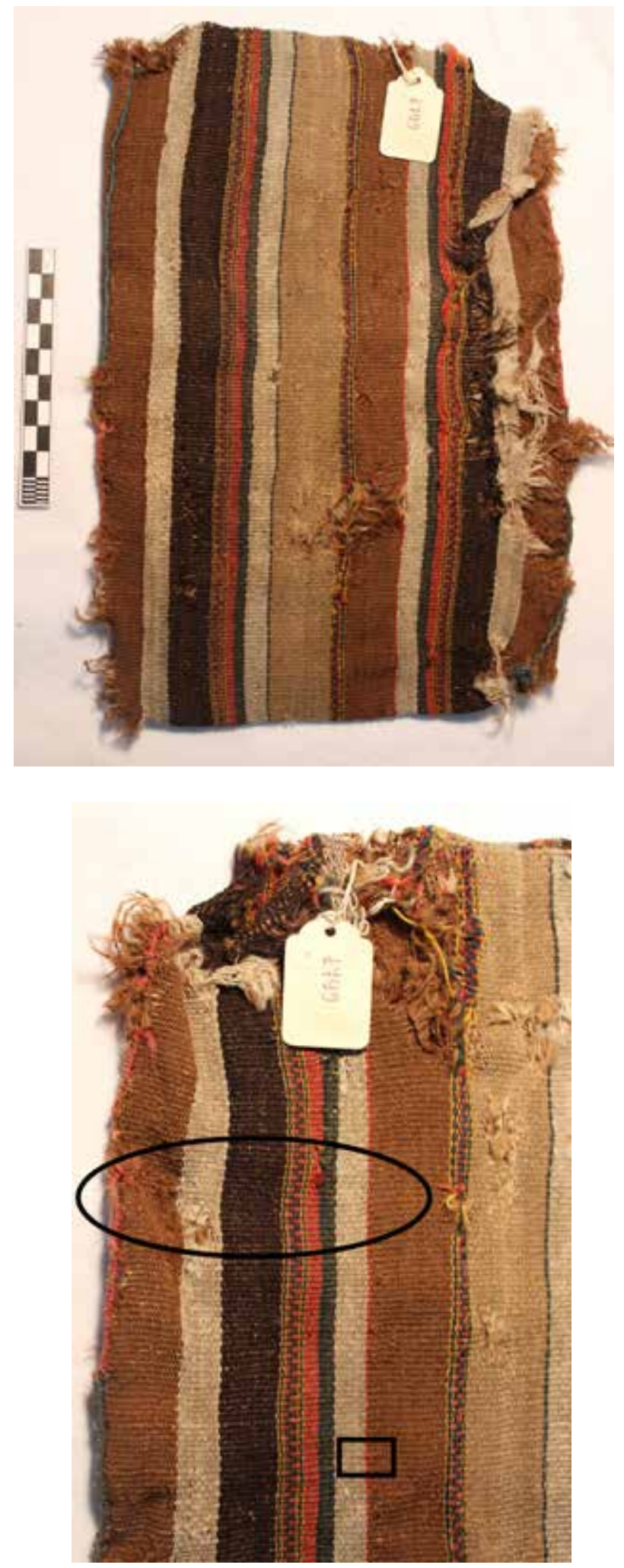

Figura 12a. Bolsa con una disposición de color asimétrica de los enterratorios de Doncellas, № 1499 (Museo Arqueológico "Dr. Eduardo Casanova", Centro Universitario Tilcara, Facultad de Filosofía y Letras, Universidad de Buenos Aires). El punto corrido envuelto de la costura es de color azul en la parte superior de la bolsa y rojo al lado izquierdo, y viceversa al lado derecho.

Figura 12b. Detalle de la bolsa de la Figura 12a, donde se nota la inserción de hilos de trama parciales o "caracoles" en la zona marcada por el óvalo y el ajuste de la urdimbre roja rota, marcado por el rectángulo. 


\section{Consideraciones finales}

El enfoque de este artículo ha sido la habilidad. Precisamente, he explorado cómo los actos cotidianos de hilar y tejer dejan huellas perceptibles de los procesos utilizados en las bolsas de Doncellas y cómo estos actos podrían relacionarse con las predilecciones estéticas de las tejedoras. La caracterización ofrecida aquí conlleva la idea de que las tejedoras estaban alertas a los significados cosmológicos de su entorno a través de su trabajo diario manejando el vellón.

Que muchas de las bolsas ya estaban en estado deteriorado cuando acompañaron a los difuntos a la tumba es un testimonio elocuente de su valor. Ante un problema similar en un estudio de ajuares en los cementerios de Arica, en el norte de Chile, Cassman quedó desconcertada por una aparente paradoja. Individuos con muchas posesiones, supuestamente ricos, llevaban a la tumba tejidos gastados o muy reparados. Ella sugirió que "estos tejidos en un mal estado probablemente pertenecían a una mujer mayor, una que ya no podía tejer para sí misma" (Cassman, 2000: 264, mi traducción). Sin embargo su estudio sobre la complejidad en la producción textil reveló que las personas que vivían de actividades marítimas en la costa eran capaces de acumular más textiles con menos reparaciones que sus homólogos que vivían de actividades agrícolas. No es obvio que el difunto junto a quien se encontró un tejido lo haya tenido durante su vida. El hecho sobresaliente es que las bolsas Doncellas fueron valoradas por sí mismas sin que el zurcido intente replicar su condición original.

De acuerdo con Haber (2010: 159), la estética no es un campo autónomo. El campo más amplio que él tuvo en cuenta reconoce que las personas adoptan diferentes posiciones cuando están sujetas a condiciones sociales hegemónicas; es importante reconocer las distancias epistémicas que prevalecen bajo tales condiciones (Haber, 2010: 162163). En muchas partes del mundo, el tejido ha tenido una identidad feminizada. En contextos arqueológicos andinos, la investigación posterior a la excavación de tumbas pertenecientes a la tradición chiribaya en el valle de Osmore, sur de Perú, indica que las mujeres probablemente hayan sido tejedoras porque están acompañadas de herramientas para hilar y tejer (Minkes, 2005: 146). Sin embargo, no podemos extrapolar este ejemplo, porque los varones eran parte de los tejedores durante el período inka.

Dado que una episteme dominante hoy en día separa las prácticas manuales de tejer del pensamiento intelectual, la división sexual del trabajo ha influido en cómo el tejido se considera una actividad intelectual. Smith (2014) ha abierto un espacio teórico entre la práctica del tejido (craft) y el material del medio (medium), ya que estos conceptos se han discutido en los debates modernistas. Comentando sobre la perspectiva de Max Weber, Smith observa que su argumento está cargado de valores porque Weber pensaba que el trabajo de los hombres tiene un fin, mientras que el de las mujeres no lo tiene. El trabajo de las mujeres le parecía ser nada más que un "modo de mantenimiento" y Smith (2014:31) sostiene que Weber lo vio como "un odioso precursor del trabajo en las fábricas del siglo XIX" sin "un propósito teórico [ni] un objetivo espiritualmente matizado".

Smith ofrece una reflexión sobre el desarrollo, durante los años veinte del siglo XX, de una "teoría del tejido" por parte de algunas tejedoras. Las tejedoras en cuestión eran profesoras y estudiantes en el taller textil de la escuela Bauhaus..$^{22}$ Estas se motivaron a contribuir con sus esfuerzos de valorizar el tejido cuando sus homólogos masculinos propusieron sus propias teorías sobre la artesanía como manual, técnica e intelectual a la vez. El riesgo era que el tejido se dejara en un vacío no teorizado. Este argumento sobre la contribución del trabajo estético de las mujeres visto a través de una lente típica de una episteme dominante tiene un análogo; Kusch (2012: 25) comentaba que la estética americana, que supone la presencia de lo "indio", era como un espacio vacío 
en el mundo occidental. Es decir, las lentes a través de las cuales se ve la producción de los tejidos son múltiples.

Smith (2014: 91-93) también considera los debates en las primeras dos décadas del siglo XX sobre la relación entre las cualidades táctiles y visuales en una obra de arte. La noción alemana de Faktur o francesa de facture, que es un subproducto de la creación de un objeto aún visible en el artículo terminado, fue utilizada especialmente por artistas rusos de vanguardia involucrados en círculos constructivistas. Al principio, la evidencia proporcionada por el manejo del material se tomó para demostrar la presencia del artista pero, cada vez más, llegó a denotar la conveniencia de la presencia material y el borrado de la subjetividad de un creador (Gough, 2005: 12).

Por lo tanto, la dificultad radica en cómo concebir a los tejedores en el pasado: ¿eran hombres o mujeres y cómo se valoraban los productos de sus manos? La complejidad de los desarrollos en el pensamiento europeo indica cuán extensa es la distancia epistémica entre el siglo XXI y el período durante el cual se tejieron los textiles de Doncellas. Existen algunas continuidades formales en las prácticas de tejido desde la época prehispánica hasta el presente. Por ejemplo, un detalle que une las bolsas tejidas en Isluga con las de Doncellas es que la "costura vaya siempre por fuera" (Cereceda, 2010 [1978]: 182). En el presente, las mujeres tejen las bolsas, pero la división sexual del tejido como se ha practicado en Isluga durante los siglos XX y XXI no es necesariamente la misma que en tiempos prehispánicos. Si he preferido la forma femenina de "tejedora" en este artículo no es como un calificador absoluto de la identidad de las personas que tejieron las bolsas de Doncellas. ${ }^{23}$ Este aspecto de la identidad de las tejedoras permanece oscuro. Lo que queda son las huellas de su presencia en los tejidos como fruto de sus manos.

Dicho esto, un aspecto que puede haber atravesado las distancias epistémicas de una u otra manera concierne al acto de hacer un textil. Los diseños en las talegas de Isluga se organizan alrededor de un eje central, que los tejedores denominan chuyma, en referencia a la unidad formada por pulmones y corazón (Dransart 1988: 44, 1995: 238, 2002: 122-123; Cereceda, 2010 [1978]: 183). Cuando los pulmones fallan, al final de la vida de una tejedora, ella ya no tiene fuerza en los hombros para continuar tejiendo. "Dejé de tejer, no tengo pulmón", me explicó una tejedora (ver también Zorn, 1992: 155). En Isluga se denomina boca (laka) a los hilos externos de la urdimbre. Esta boca se abre y se cierra a medida que la tejedora abre y cierra la calada formada por los hilos de la urdimbre para insertar la trama. Es como si la trama fuera como una bocanada de aire entrando en la tela. La acción repetida da vida a la tela. Debido a que se han reportado ontologías animadoras comparables en otras comunidades altiplánicas (Meisch, 1986b: 248-249; Arnold, 2018: 246-247), es muy probable que las tejedoras de los textiles de Doncellas los hayan tejido en contextos sociales con un objetivo espiritualmente matizado.

Hay una pregunta más para considerar. ¿El sentimiento estético es inmanente o es un sentimiento elevado más allá de la experiencia diaria? En una reseña de Mandoki (2008), Corballis cuestiona el proyecto de dar pleno reconocimiento a la estética en la vida cotidiana. Explica que Mandoki está convencida de que el sentimiento estético es inmanente, a diferencia de los vanguardistas que buscan importar la estética a la vida cotidiana. Corballis sostiene que el vanguardismo se basa en un concepto de una estética intensa, más allá de lo normal, lo que significa que sus defensores están decepcionados con la realidad de "nuestras vidas comprometidas". Sugiere que la respuesta del lector a los argumentos de Mandoki (2008) depende de si la visión de Mandoki de lo cotidiano queda más clara que la decepcionada visión del vanguardista: "Dependerá de cómo nos sintamos y de lo que creamos sobre la promesa del arte a ser algo más que lo cotidiano" (Corballis, 2008: 149). 
En este artículo he considerado cómo una experiencia estética basada en los actos del hacer brota de un entorno lleno de significados en la manipulación del vellón y del hilo. Sugiero que la experiencia de lo estético es inmanente precisamente porque surge de las prácticas cotidianas. No obstante, habría que ser una hilandera y tejedora para responder plenamente a la pregunta de Corballis. Y para una mayor comprensión aún de la estética cotidiana, sospecho que habría que ser además una tejedora que no pudiese recurrir a las telas importadas de fabricación industrial para vestirse.

\section{Agradecimientos}

Estoy profundamente agradecida a Lucila Bugallo por animarme a estudiar los textiles de Doncellas en el Museo Arqueológico y Antropológico "Dr. Eduardo Casanova" de Tilcara y deseo agradecer al personal de dicho Museo por hacer posible el estudio. También le agradezco sinceramente por obtener una copia de Rolandi de Perrot (1973), que desgraciadamente es difícil de conseguir, pero que leí originalmente en 1987. Igualmente, agradezco a Mario Vilca por su asesoramiento en algunos otros temas de lectura. Las observaciones sobre las bolsas de Doncellas en el Museo Etnográfico "Juan B. Ambrosetti" de Buenos Aires las realicé en una visita a esa ciudad en 1987 y agradezco a Margarita Ozcoidi por presentarme al personal de dicho Museo. Mi reconocimiento a Carolina Agüero por ayudarme a contextualizar los textiles considerados aquí. Estoy profundamente en deuda con las tejedoras de Isluga, especialmente con la difunta Natividad Castro Challapa, la difunta Gabriela Mamani Challapa, la difunta Soria Mamani Challapa, Juana Mamani e Isabel Challapa Castro, así como con miembros de sus familias, por ser mis maestras. Quisiera agradecer a los evaluadores/ as de mi manuscrito por sus sugerencias. No obstante, soy responsable de cualquier error o infelicidad. 


\section{Dibliografía}

»Agüero, C. (2007). Los textiles de Pulacayo y las relaciones entre Tiwanaku y San Pedro de Atacama. En Boletín del Museo Chileno de Arte Precolombino 12(1), pp. 85-98. Santiago de Chile.

$»$-----. (2015). Vestuario y sociedad andina. Desarrollo del Complejo Pica-Tarapacá (80o-140o DC). San Pedro de Atacama, QILLQA Ediciones IAA, Universidad Católica del Norte.

》-----. (2018). Intervention in local textile-making as a Tahuantinsuyu strategy for linking northwest Argentina with the Atacama Desert, northern Chile (A.D. 1350 -1500). En Quaternary International. Disponible En https://doi.org/10.1016/j. quaint.2018.09.024

"Albers, A. (1965). On weaving. Middletown, Wesleyan University Press.

» Alfaro de Lanzone, L. C. (1983). Investigación arqueológica en la cuenca del Río Doncellas (Provincia de Jujuy). Integración de la Puna jujeña a los centros culticos andinos. En Relaciones de la Sociedad Argentina de Antropología XV, N.S., pp. 25-47. Buenos Aires.

»-----. (1988). Investigación en la Cuenca del Río Doncellas. Reconstrucción de una cultura olvidada en la Puna jujeña. San Salvador de Jujuy, Gobierno de la Provincia de Jujuy, Instituto Nacional de Antropología/Buenos Aires, Departamento de Antropología y Folklore, Jujuy/Organización de los Estados Americanos.

» Antoja, T.; Helmi, A.; Romero-Gómez, M.; Katz, D.; Babusiaux, C.; Drimmel, R.; Evans, D. W.; Figueras, F.; Poggio, E.; Reylé, C.; Robin, A. C.; Seabroke, G. y Soubiran, C. (2018). A dynamically young and perturbed Milky Way disk. En Nature 561, № 7723, pp. 360-362.

»Arellano López, J. (2000). Arqueología de Lipes altiplano sur de Bolivia. Quito, Museo Jacinto Jijón y Camaño, Pontificia Universidad Católica del Ecuador y Taraxacum.

"Arnold, D. Y. (2018). Making textiles into persons: gestural sequences and relationality in communities of weaving practice of the South Central Andes. En Journal of Material Culture 23(2), pp. 239-26o.

»Arnold, D. Y. y Espejo, E. (2015). The Andean science of weaving. Londres, Thames and Hudson.

» Arnold, D. Y. y Yapita, J. de D. (1998). Río de vellón, río de canto: cantar a los animales, una poética andina de la creación. La Paz, Hisbol/ILCA.

» Bird, J. B.; Hyslop, J.y Dimitrijevic Skinner, M. (1985). The Preceramic Excavations at the Huaca Prieta Chicama Valley, Peru. En Anthropological Papers of the American Museum of Natural History 62.

»Boman, É. (1908). Antiquités de la région andine de la République argentine et du Désert d'Atacama. Tomo II. París, Imprimerie nationale.

» Bosio, L.; Seldes, V.; Mamani, H.; Urroz, C. y Pereyra, J. (2008-2009). Análisis de un cuerpo momificado procedente de Doncellas (Dep. de Cochinoca, Pcia de Jujuy, Argentina). En Anales de Arqueología y Etnología 63-64, pp. 137-149.

»Bugallo, L. (2010). La estética de la crianza. Los santos protectores del ganado en la Puna de Jujuy. En Bovisio, M. A. y Penhos, M. (comps.). Arte indígena: categorías, practicas, objetos, pp. 85-102. Córdoba, Encuentro Grupo Editor, Colección Contextos humanos, Serie intercultura = Memoria + Patrimonio. 
»----. (2016). Wak'as en la puna jujeña. Lo fluido y lo fino en el diálogo con Pachamama. En Bugallo, L. y Vilca, M. (comps.). Wak'as, diablos y muertos. Alteridades significantes en el mundo andino, pp. 111-161. San Salvador de Jujuy, Universidad Nacional de Jujuy e Instituto Francés de Estudios Andinos.

"Cassman, V. (2000). Prehistoric Andean ethnicity and status: the textile evidence. En Drooker, P. B. y Webster, L. D. (comps.). Beyond cloth and cordage: Archaeological textile research in the Americas, pp. 253-266. Salt Lake City, University of Utah Press.

»Cereceda, V. (2010 [1978]). Semiología de los textiles andinos: las talegas de Isluga. En Chungara: Revista de Antropología Chilena 42(1), pp. 181-198. Arica.

»Cigilano, E. y Raffino, R. (1973). Tastil: un modelo cultural de adaptación, función y desarrollo de una sociedad urbana prehistórica. En Relaciones de la Sociedad Argentina de Antropología 6 N.S., pp. 159-185.

»Corballis, T. (2008). Reseña: Katya Mandoki, Everyday aesthetics: prosaics, the play of culture and social identities (Aldershot, Ashgate, 2007). En Thesis Eleven 95(1), pp. 147-149. Cambridge. Disponible En https://doi.or g/10.1177/07255136080950011302

"Desrosiers, S. (2013). El textil como matriz para el desarrollo de las artes plásticas en los Andes. En Revista Española de Antropología Americana 43(2), pp. 477-514. Disponible en: http://dx.doi.org/10.5209/rev_REAA.2013.v43.n2.44020

»Doyon-Bernard, S. J. (1990). From twining to triple cloth: experimentation and innovation in ancient Peruvian weaving (ca. 5000-400 B.C.). En American Antiquity 55(1), pp. 68-87.

»Dransart, P. (1988). Continuidad y cambio en la producción textil tradicional aymara. En Hombre y Desierto: una Perspectiva Cultural 2, pp. 41-57. Antofagasta.

»----. (1995). Inner worlds and the event of a thread in Isluga, northern Chile. En Dransart, P. (comp.). Andean art: visual expression and its relations to Andean beliefs and values, pp. 228-242. Aldershot, Avebury.

»----. (2002). Earth, water, fleece and fabric. An ethnography and archaeology of Andean camelid herding. Londres, Routledge.

»---..(2014). Thoughts on productive knowledge in Andean weaving with discontinuous warp and weft. En Arnold, D. Y. y Dransart, P. (comps.). Textiles, Technical Practice and Power in the Andes, pp. 216-232. Londres, Archetype Publications.

»Emery, I. (1980). The primary structure of fabrics. An illustrated classification. Washington, The Textile Museum.

"Espejo, E. y Arnold, D. Y. (2014). Woven techniques and social interactions in the South Central Andes: ladder designs and the visualisation of productive output. En Arnold, D. Y. y Dransart, P. (comps.). Textiles, technical practice, and power in the Andes, pp. 303-326. Londres, Archetype.

»Espoueys, O.; Horta, H. y Reciné, V. (1995). Estudio de una pieza textil de filiación tiwanaku del Valle de Azapa, Arica, Chile. En Boletín del Museo Chileno de Arte Precolombino 6, pp. 111-125.

»Gough, M. (2005). The artist as producer: Russian constructivism in Revolution. Berkeley, University of California Press.

»Haber, A. F. (2010). Disciplina, plasticidad y alteridad. Un epílogo para el arte indígena. En Bovisio, M. A. y Penhos, M. (comps.). Arte indígena: categorías, prácticas, objetos, pp. 157-163. Córdoba, Encuentro Grupo Editor, Colección Contextos humanos, Serie intercultura $=$ Memoria + Patrimonio. 
» Hernández Llosas, M. I. (1983-1985). Las calabazas prehispánicas de la Puna Centro meridional (Jujuy, Argentina). Análisis de sus representaciones. En Anales de Arqueología y Etnología 38 (40), pp. 77-158. Mendoza, Universidad Nacional de Cuyo.

» Killian Galván, V. A.; Samec, C. T. y Panarello, H. O. (2016). When maize is not the first choice: advances in paleodietary studies in the archaeological site Río Doncellas (Jujuy, Argentina). En Anthropological Review 79(3), pp. $265-279$.

»Kusch, R. (2012). Planteo de un arte americano. Rosario, Fundación Ross.

»López Campeny, S. M. L. (2005). Estructuras, representaciones y contextos. Perspectivas teórico-metodológicas para el análisis de textiles arqueológicos. En Solanilla Demestre, V. (ed.). Tejiendo sueños en el Cono Sur: textiles andinos: pasado, presente y futuro, pp. 59-82. Bellaterra, Grup d'Estudis Precolombins, Universitat Autònoma de Barcelona.

»----. (2014). The agency of textile technology in some archaeological ritual contexts of Northwest Argentina. En Journal of Antropology and Archaeology 2(2), pp. 39-57. Madison.

"López Campeny, S. M. L. y Martel, A. R. (2014). La vestimenta del poder. Comparando los registros textil y rupestre en el noroeste de Argentina (siglos XIII a XV). En Relaciones de la Sociedad Argentina de Antropología XXXIX (1), pp. 21-55.

»Mandoki, K. (2008). Estética cotidiana y juegos de la cultura: prosaica I. México.

»Martínez, G. (1980). Paisaje y pensamiento para una semántica del espacio aymara. Lima, Pontificia Universidad Católica del Perú.

» Meisch, L. A. (1986a). Spinning in Bolivia. En Spin-Off 10(1), pp. 25-29.

»----. (1986b). Weaving styles in Tarabuco, Bolivia. En Rowe, A. P. (ed.). The Junius B. Bird Conference on Andean Textiles, pp. 243-274. Washington, D.C., The Textile Museum.

" Minkes, W. (2005). Wrap the dead. The funerary textile tradition from the Osmore Valley, South Peru, and its social political implications. Leiden, Archaeological Studies Leiden University 12.

» Nielsen, A. E. (2001). Evolución del espacio doméstico en el norte de Lípez (Potosí, Bolivia): ca 900-170o DC. En Estudios Atacameños 21, pp. 41-61. San Pedro de Atacama.

» Nielsen, A. E.; Angiorama, C. I.; Maryañski, J.; Ávila, F. y López, M. L. (2015). Paisajes prehispánicos tardíos en San Juan Mayo (frontera Argentina-Bolivia). En Arqueología 21 Dossier, pp. 33-65.

» Niemeyer, H. y Schiappacasse, V. (1963). Investigaciones arqueológicas en Is terrazas de Conanoxa, Valle de Camarones (Provincia de Tarapacá). En Revista Universitaria, año 48, pp. 101-66.

"Ottonello de García Reinoso, M. y Ruthsatz, B. (1982). Environment, human settlement, and agriculture in the Puna de Jujuy, Argentina: a case study of land-use change. En Mountain Research and Development 2(1), pp. 111-126.

"Pérez de Micou, C. (2001). Cestería y cordelería para los muertos. En Chungara 33(1), pp. 137-144. Arica. Disponible en: https://dx.doi.org/10.4067/So71773562001000100023

»----. (2009). Indicios arcaicos en la Colección Doncellas, Jujuy (República argentina). El 'Yacimiento' 26 a la luz de un fechado radiocarbónico $(4811+39$ AP). En Bulletin de l'Institut Français d'Études Andines 38(1), pp. 75-85. 
"Pérez, M. (2013). Aproximación tecnomorfológica a los vasitos chatos de Doncellas (Puna Septentrional argentina) a través de técnicas arqueométricas. En Revista Española de Antropología Americana 43(2), pp. 385-404.

»Pérez, M. y Killian Galván, V. A. (2011). Doncellas (Puna Septentrional, Jujuy, Argentina): nuevos enfoques a partir del estudio cerámico y del análisis paleodietario. En; Estudios Atacameños 42, pp. 79-100. San Pedro de Atacama.

»Pérez, M. y Velázquez Cabrera, R. (2015). Análisis de llamas resonadoras de arcilla (Jujuy, puna septentrional argentina). En Arqueología 21(1), pp. 13-29.

»Peters, A. H. y Tomasto-Cagigao, E. I. (2017). Masculinities and femininities: Forms and expressions of power in the Paracas Necropolis. En Scher, S. E. M. y Follensbee, J. A. (comps.). Dressing the part: Power, dress, gender and representation in the pre-Columbian Americas, pp. 371-449. Gainesville, University Press of Florida.

» Rolandi de Perrot, D. (1973). Capítulo VI. Los textiles tastileños. En Cigliano, E. M. (comp.). Tastil, una ciudad preincaica argentina, pp. 229-399 + láminas. Buenos Aires, Cabargon.

»-----. (1979). Los tejidos del Río Doncellas, Dto. Cochinoca, Provincia de Jujuy. En Actas Jornadas de Arqueología del N.O.A., Antiquitas 2, pp. 22-73. Buenos Aires.

"Smith, T'A. (2014). Bauhaus weaving theory. From feminine craft to mode of design. Minneapolis, University of Minnesota Press.

»Splitstoser, J. C.; Dillehay, T. D.; Wouters, J. y Claro, A. (2016). Early Pre-Hispanic Use of Indigo Blue in Peru. En Science Advances 2 e1501623.

»Standen, V. G. (2003). Bienes funerarios del cementerio chinchorro Morro 1: descripción, análisis e interpretación. En Chungara, Revista de Antropología Chilena 35(2), pp. 175-207. Arica.

»Zaburlín, M. A. (2012). La cerámica tricolor de la puna jujeña: variabilidad de los motivos con vírgulas y puntos blancos. En Arqueología 18, pp. 131-152.

»----. (2016). Vasijas zoomorfas prehispánicas de la Puna de Jujuy (Argentina). Una propuesta de análisis semiótica. En Boletín del Museo Chileno de Arte Precolombino 21(2), pp. 137-152. Santiago de Chile.

"Zorn, E. (1992). Textiles as a daily obsession: a day in the life of an Andean weaver. En Textile Society of America Symposium Proceedings, 588. Disponible en: http://digitalcommons.unl.edu/tsaconf/588

\section{Penelope Dransart}

Diplomada en Arte (Grays School of Art, Robert Gordon University, Escocia). Posgrado para la Enseñanza del Arte (Jordanhill College of Education, Strathclyde University, Escocia). Máster en Arqueología Antropológica (University of Oxford). Becaria PirieReid de la University of Oxford. Doctora en Etnología por la University of Oxford. Entre 2004 y 2013 miembro del Peer Review College del Arts and Humanities Council del Reino Unido. Profesora Universitaria en la University of Wales Trinity Saint David. Actualmente profesora honoraria de University of Aberdeen. Su tesis doctoral Earth, Water, Fleece and Fabric. An ethnography and archaeology of Andean camelid herding (Routledge, 2002) aborda la domesticación y pastoreo de los camélidos en los Andes en relación con el vellón y las actividades de hilar y tejer. Becaria de la Wenner-Gren Foundation (2017) para realizar trabajo de campo en Isluga, Chile. Es autora de numerosos artículos y compilaciones. 
1 La ocupación humana en la vecindad parece ser mucho más antigua porque Pérez de Micou (2009) informó una fecha C-14 de $4811 \pm 39$ AP sobre una muestra proveniente de una tumba que difería del resto de los enterratorios. El poblado cercano, denominado "Yacimiento del río Doncellas", fue además fechado en 1000 AP por Alfaro de Lanzone (1988).

2 Diana Rolandi de Perrot (1979: 22-23) estudió un total de 150 piezas, incluyendo las bolsas, procedentes de Río Doncellas, comentando que había otras piezas en los catálogos de los museos, probablemente también de la misma zona.

3 Existen varias publicaciones sobre los contenidos de las tumbas, incluyendo hilos y textiles (Rolandi de Perrot, 1979; López Campeny, 2005; López Campeny y Martel, 2014), cestería (Pérez de Micou, 2001), calabazas (Hernández Llosas, 1983-1985), cerámica (Pérez y Killian Galván, 2011; Zaburlín, 2012; Pérez, 2013; Pérez y Velázquez Cabrera, 2015) y dieta (Killian Galván et al., 2016). Véase también Boman (1908).

4 Isluga es una comunidad bilingüe de hablantes de aymara y de español en el altiplano de lquique, al norte de Chile, colindante con Bolivia. El pastoreo de llamas y alpacas constituye la principal actividad económica, complementada con el cultivo de quinua y papas. He realizado trabajo de campo en Isluga por períodos de tiempo diferentes en 1986, 1987-1988, 1989, 1995, 1996, 1997, 2003 y 2017.

5 Para un estudio pormenorizado de los textiles de Tastil, ver Rolandi de Perrot (1973), aunque cabe señalar que las bolsas no se presentan entre los textiles. La expedición de Karl Schuel a Bilcapara en 1919 descubrió bolsas comparables a las de Doncellas; están ahora en el Museo de La Plata (№ 3228, № 3233). El sitio residencial de Bilcapara fue considerado por Nielsen et al. (2015).

6 En el torzal, la trama consiste en un par de elementos, que se envuelven entre sí, encerrando los hilos de la urdimbre (Emery, 1980: 200-201). A veces se utiliza el término "encordelado" para esta técnica.

7 Rolandi de Perrot (1979) usa el término "peinecilla”.

8 La bolsa es la № 2849, de la tumba DJ-23, sitio AZ-3, en la Colección Manuel Blanco Encalada, Museo Nacional de Historia Natural, Chile.

9 Nielsen (2001: 44) se refiere a esta región arqueológica bajo el término “zona norte de Lípez".

10 La talega ilustrada por Espejo y Arnold (2014:320) de las colecciones del Museo Británico (№ Am1981, 28.140) procede del Departamento de Oruro; la talega fue comprada a los coleccionistas Robert y Marianne Huber.

11 En Isluga esta configuración se llama k’uthu (Dransart, 1988), pero en Qaqachaka, Bolivia, las tejedoras conocen este peinecillo por el término patapata (Espejo y Arnold, 2015: 313). 
12 Museo Etnográfico “Juan B. Ambrosetti”, № 43.1374.

13 En la bolsa del Museo Arqueológico y Antropológico “Dr. Eduardo Casanova”, № $2103,42-558$.

14 Los varones también están acostumbrados a estos métodos que tienden a estar asociados con otras formas de hilar que no se consideran aquí. Ver Dransart (2002: 118-119, 123).

15 Museo Arqueológico y Antropológico “Dr. Eduardo Casanova”, № 1477, 41-507.

16 Museo Arqueológico y Antropológico “Dr. Eduardo Casanova”, № 1487, 42-2507.

17 A pesar del carácter rectilíneo de entrelazar la urdimbre y la trama, las tejedoras pueden lograr transformaciones notables, como señaló Albers (1965: 57-58), quien apreciaba la habilidad de las tejedoras prehispánicas en el norte de Chile para convertir la índole cuadrangular de una tela en túnicas trapezoidales a través del proceso de tejer, en lugar de cortar y dar forma a la túnica después de retirarla del telar. El acto de transponer la urdimbre en el proceso de tejer constituye otra transformación notable. Anni Albers fue una de las tejedoras de la escuela Bauhaus. La importancia de estas tejedoras se considera más adelante en la última sección de este artículo.

18 Museo Etnográfico “Juan B. Ambrosetti”, № 43.1385.

19 Museo Arqueológico y Antropológico “Dr. Eduardo Casanova”, № 1606.

$20 N^{\circ} 1047 a$ y b en Rolandi de Perrot (1973: 336-337). Los textiles están conservados en el Museo de La Plata.

21 Museo Arqueológico y Antropológico “Dr. Eduardo Casanova”, № 1799.

22 Una de las más conocidas de estas tejedoras, Anni Albers, quien más tarde escribiría On weaving (1965), se dio cuenta de que la introducción de los lizos en las tradiciones asiáticas y europeas llegó a asociarse con la mecanización y la restricción de ciertas posibilidades, pero las antiguas tejedoras andinas utilizaban lizos sin imponer tantas restricciones (Smith, 2014: 165-167). Albers dedicó su libro a "sus maestros", los/las tejedores/as del pasado andino. Otro aspecto muy importante del libro de Albers es que destacó la importancia de hilar como una actividad que codifica significados (Dransart, 1995).

23 De manera similar, Smith (2014: xxxi) explica que su consideración de la identidad feminizada del acto de tejer debe entenderse en un sentido en el que "ni lo masculino ni lo femenino (...) se entienden como calificativos absolutos" (énfasis original, traducción mía). 